\title{
4
}

\section{Landesverrat Fall Nr. 3418/45}

\section{Inhaltsverzeichnis}

Anzeige ...................................... 249

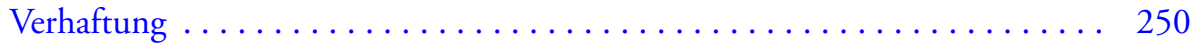

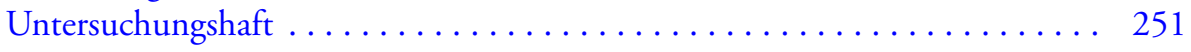

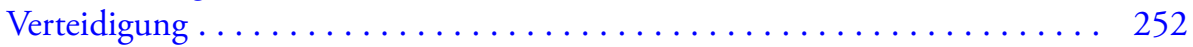

Anklageerhebung................................. 253

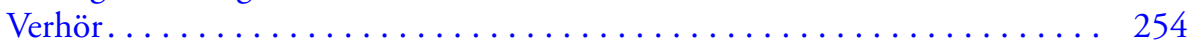

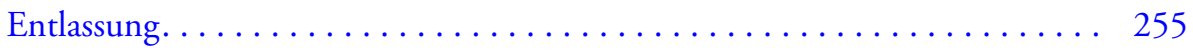

Einsetzung des Sachverständigenkomitees . . . . . . . . . . . . . . 257

Der Bericht des Komitees . . . . . . . . . . . . . . . . . . . . . 258

Die Schlussfolgerung des Komitees . . . . . . . . . . . . . . . . . . . . 265

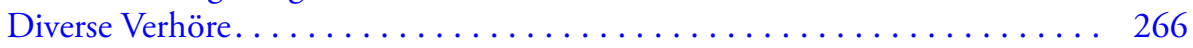

Verzicht auf Hauptklage ............................. 271

Keine Anklage. ................................ 271

Akzeptanz des Bußgeldbescheids . . . . . . . . . . . . . . . . . . . 275

Fall abgeschlossen ................................. 277

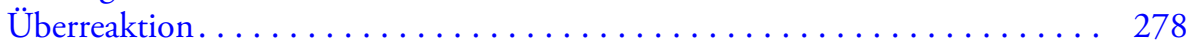

Nicht alles ist Rechtswissenschaft ...................... 281

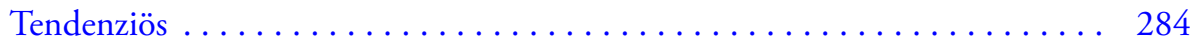

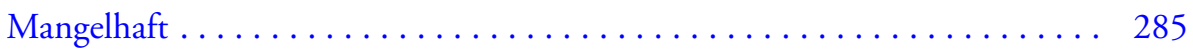

Unlogisch ................................... 286

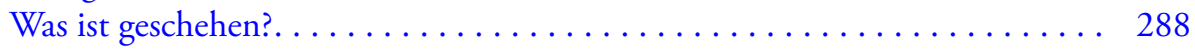

Die Pass-Frage. . . . . . . . . . . . . . . . . . . . . . . . . . . . . 289

Keine mildernden Umstände. . . . . . . . . . . . . . . . . . . . . 295

Verleumdet und nachhaltig geschädigt ................... 296 


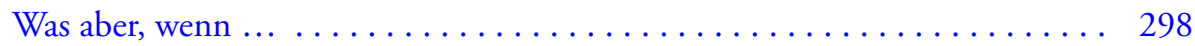

Fachliche Ächtung aus politischem Kalkül? . . . . . . . . . . . . . . . . . 298

Fünf Physiker . . . . . . . . . . . . . . . . . . . . . . 300

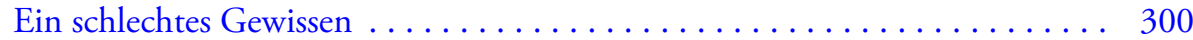

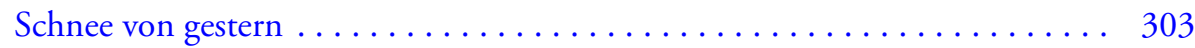

Sind Fakten dasselbe wie die Wahrheit?.................... 307

50 Jahre vergehen. Nur ganz wenige Norweger, außerhalb der Familie, verbinden überhaupt etwas mit dem Namen Rolf Widerøe. Einer aber erinnert sich. Tor Brustad vom Radiumhospital konnte den Mann im weißen Kittel mit dem Schraubenschlüssel in der Hand, der kopfüber in der Strahlenbehandlungsmaschine gestanden hatte, nicht vergessen. Heute als pensionierter Professor ist er wie damals, als er neu angestellt war, der Ansicht, dass mit Widerøe irgendetwas nicht stimmt: in Norwegen eine solche Unperson und in ausländischen Fachkreisen derart anerkannt. Jetzt will er der Sache auf den Grund gehen. Messbare Fakten finden. Irgendjemand oder irgendetwas muss erklären können, was dieser Mann Falsches getan hat. Er saß im Gefängnis, worin aber bestand das Verbrechen? Das Gerede der Leute ist eine Sache. Wofür aber wurde er verurteilt? Er war nicht Mitglied der norwegischen Nazi-Partei Nasjonal Samling. Was von „kriegswichtiger“ Bedeutung hatte er also getan? Stimmt es, dass er daran beteiligt war, Waffen für die Deutschen herzustellen? Der Wissenschaftler Brustad geht gewohnheitsgemäß vor. Sucht nach Quellen aus erster Hand. Begibt sich ins Norwegische Zentralarchiv. Will die Gerichtsakten sehen.

Bevor Tor Brustad jedoch berichtet, was er in den Archivregalen gefunden hat, verweist er auf die Stimmung nach fünf Jahren Besatzung, der Antipathie gegen alles, was mit Deutschland und Deutschen zu tun hatte. Das betraf auch die Norweger, von denen man wusste, dass sie mit den Deutschen zusammengearbeitet hatten, oder sie dessen verdächtigte. Er ist alt genug, um das zu wissen. Er selbst war um die 20 Jahre alt, als der Frieden kam. Ein paar Generationen später findet er es angemessen, an die spezielle Atmosphäre zu erinnern. Er hat so viele Studentenjahrgänge unterrichtet, die nach dem Krieg geboren wurden, dass er um die Notwendigkeit weiß. Damals war es schwer, emotional unberührt zu bleiben. Und das ist es auch heute noch. Für diejenigen, die es erlebt haben. Er spürt es selbst.

So hat er sich, was ihn selbst betrifft, abgesichert und jüngeren Generationen geholfen, die Sinne zu schärfen. In einer Zeit, in der Knut Hamsun noch immer Zwietracht sät, Kirsten Flagstads Name noch immer mit Untertönen versehen ist und Hanna Kvanmos "Jugendsünde" noch 
nicht vergessen ist. In einer Zeit, als es mehr Bücher über den Zweiten Weltkrieg gibt als jemals zuvor, in der Max Manus via Kinoleinwand neue junge Bewunderer gewinnt und der Krieg der Eltern und Großeltern Interesse weckt. Endlich herrscht das Klima, sich „dem Gefährlichen“ zu nähern. 1996, in Rolfs Sterbejahr, ein halbes Jahrhundert, nachdem der Prozess gegen ihn beendet worden war, bat Tor Brustad die Behörden um Zugang zu den Dokumenten. Ja, das war in Ordnung, das Zentralarchiv wollte den Einblick in unter Verschluss befindliche Dokumente gewähren, sofern die Familie zustimmte. Das tat sie. Ohne Umschweife. Es gab nichts zu verbergen.

Rolfs Fall schien gründlich behandelt worden zu sein. Die Mappe des Landesverrat-Falls Nr. 3418/45 enthält mehrere hundert Seiten, als geheim gestempelte Dokumente. Soweit bekannt, hat sie nach ihrer Archivierung niemand gesehen oder darin geblättert. Brustad hatte Waloscheks Biografie gelesen, als sie 1993 erschienen war, was das Mysterium in gewisser Hinsicht noch größer gemacht hatte. Das Ganze hatte ihn nur noch neugieriger gemacht herauszufinden, was wirklich geschehen war. Er wollte mehr erfahren und sich die Dokumente eines nach dem anderen vornehmen. Er wollte Klarheit über den anderthalb Jahre andauernden Prozess, die kompletten 18 Monate von Mai 1945 bis November 1946.

Was steht in den formalen Gerichtsdokumenten? Was haben die Sekretäre nach Diktat auf dünne Schreibmaschinenbögen mit eingelegtem Durchschlagpapier getippt? Was gibt es an hinzugefügter Dokumentation, an eingeholten Aussagen? Hat Rolf selbst sich schriftlich geäußert? Welche Personen sind involviert? Sind es Norweger? Deutsche? Alliierte? Auf was Brustad aus ist, sind schlichtweg Fakten. Dem können Deutung, eventuell moralische Verurteilung oder Verteidigung, Zweifel und Glaube folgen, wie sie wollen. Jetzt geht es darum, nachweisbare Fakten auf den Tisch zu legen, wie sie sich in den Papieren der Akte im Zentralarchiv verbergen. Das Einzige, was er wirklich wusste, war, dass Rolf im Gefängnis gesessen hatte, denn das hatte er selbst gesagt. Und dass ihn jemand angezeigt hatte, denn auch das hatte er gesagt. Professor Brustad beginnt ganz am Anfang. Arbeitet sich Schritt für Schritt durch die Unterlagen.

\section{Anzeige}

Das Ganze begann mit einer aufsehenerregenden Anzeige, die darauf hinauslief, dass Rolf an der Entwicklung der deutschen V2-Rakete beteiligt gewesen sein soll, die gegen Ende des Krieges zum Einsatz kam. Hitlers 
Trumpfkarte, die „Vergeltungswaffe 2“, wie Propagandaminister Goebbels sie nannte. 3000 solcher ballistischen Raketen waren im Winter 1944/45 abgefeuert worden und hatten in London und Antwerpen für viele Tote und große Zerstörungen gesorgt. Rolf war im April aus Deutschland zurückgekehrt, einige Wochen vor Kriegsende. Am 20. April wurde die Anzeige bei der Polizeibehörde Oslo aufgegeben. Sie war per Hand verfasst und nicht unterschrieben, der Wortlaut jedoch eindeutig:

„Der Ingenieur Rolf Widerøe, Norsk Elektrisk und Brown Boveri, Skøyen, hat wichtige Erfindungen betreffs der V-Bombe gemacht. Er hat das Gyroskop der V2 erfunden."

Er soll mit anderen Worten den Steuermechanismus der Superrakete erfunden haben. Nichts weniger. Sehr viel schlimmer konnte der Vorwurf kaum sein. Polizei und Staatsanwaltschaft mussten reagieren. Das Original liegt der Akte nicht bei, jedoch findet sich eine maschinengeschriebene Kopie der Anzeige, die von einer namentlich genannten Person beglaubigt wurde. Weiter heißt es:

„Er wird sehr gut behandelt, bekommt alles, was er wünscht, reist oft nach Dänemark und war eine Zeit lang in Peenemünde und Hamburg stationiert, wo er seine Sachen gebaut hat. Er reiste immer mit deutschen Flugzeugen und erhält keine Erlaubnis, durch Schweden zu reisen." ${ }^{11}$

\section{Verhaftung}

Mit der anonymen Anzeige als Grundlage wurde kurz darauf der „Befehl zur Verhaftung/Anklageerhebung/Durchsuchung/Beschlagnahme“ erlassen. Dieser ist auf den 23. Mai 1945 datiert und beinhaltet folgende kurze Begründung: „Hat wichtige Erfindungen betreffs V-Bomben gemacht.“

Bereits in der darauffolgenden Nacht - von Mittwoch, dem 23., auf Donnerstag, den 24. Mai - kam die Polizei zu ihm nach Hause nach Røa, nahm ihn mit und beschlagnahmte seinen Pass.

Der Beschluss der Polizei lautete: „30 Tage Gefängnis, mit Rechtsgrundlage in prov. Verordn. vom 26/2-43 \$3-4-5-6.“ Der Transportbefehl lautete: „Wird zur Inhaftierung nach Ila geschickt." Stellvertretend für den Polizeipräsidenten von einem Polizeibevollmächtigten unterzeichnet. $^{2}$ 


\section{Untersuchungshaft}

Im Landesverratsgefängnis Ilebu wurde Rolf unmittelbar in Untersuchungshaft genommen. Unterzeichnet wurde der Haftbefehl vom Gefängnis mit: „Aufgenommen, am 24.5., 00:10 Uhr.“

$\mathrm{Zu}$ diesem Zeitpunkt befanden sich etwa 3000 Gefangene in dem Lager. Die Verhaftungen verdächtiger Personen hatten bereits am 9. Mai begonnen nach Listen, die von Hjemmefronten und norwegischen Behörden aufgestellt worden waren. Insgesamt wurden 28.750 Personen verhaftet. Die ersten Vorbereitungen für eine gerichtliche Verfolgung übernahm die Regierung in London. Später geschah das meiste auf Initiative der Leitung von Hjemmefronten.

Am nächsten Tag verfasste er eine Antwort auf die ihm gestellten Fragen. Er begann am Anfang; die wesentlichen Punkte sind nachfolgend wiedergegeben:

„Im Herbst 1922 erfand ich den Strahlentransformator (...) Machte in Aachen 1927 mit einer experimentellen Untersuchung dessen, die gleichwohl zu einem negativen Ergebnis führte, meinen Doktor. 1940/41 gelang es dem Amerikaner Kerst, dass der Apparat funktionierte. 1942/43 machte ich eine Reihe von Erfindungen in diesem Bereich, die u. a. die Leistung und die Effektivität deutlich erhöhen. Hier muss erwähnt werden, dass der Apparat, der schnelle Elektronen von vielen Millionen Volt Spannung erzeugt, ausschließlich von wissenschaftlichem, physikalischem Interesse ist. (...)

Ende September 43 bekam ich Besuch von einigen deutschen zivilen Herren, die mich nach diesen Dingen ausfragten, wobei sie angaben, von einer Studiengesellschaft für Röntgenforschung zu sein. Am Tag darauf wurde ich gezwungen, mit dem Flugzeug nach Berlin zu reisen. In Deutschland wurde mir erklärt, dass ich fortan in deutschen Fabriken an diesen Dingen arbeiten solle. Es wurde ein Vertrag mit einem Herrn Hollnack aufgesetzt, den ich unterzeichnete. Unter anderem versprach man mir, meinen Bruder von zehn Jahren Zuchthaus zu befreien. Dieses Versprechen wurde nicht gehalten. Die Verbindung zu Direktor Solberg wurde mit einer Dienstverpflichtung geregelt.

Von Oktober 43 bis April 45 habe ich dann mit mehreren Unterbrechungen an der Entwicklung des erwähnten Transformators in Hamburg gearbeitet, zuletzt in Kellinghusen. Es wurde ein 15-MeV-Transformator gebaut und er funktionierte. Unmittelbar vor dem Zusammenbruch in Deutschland erhielt ich die Erlaubnis, nach Hause zu reisen, und es gelang mir, alle wesentlichen Papiere über meine Arbeit mitzunehmen.

Es ist nun meine Absicht, eine Gesamtdarstellung dieser Arbeit zu verfassen und die Ergebnisse der norwegischen wissenschaftlichen Forschung 
zur Verfügung zu stellen. Ich verweise auf Prof. Hylleraas und Dr. Wergeland an der Universität. Letztgenannter bezeichnete meine Arbeit als ungeheuer wichtig für die wissenschaftliche Forschung und sagte, diese Arbeit müsse für Norwegen gerettet werden. (...) Im Übrigen ist die Schweizer Firma Brown Boveri im Besitz bestimmter Rechte an diesen Erfindungen. (...) Daher bitte ich um die Erlaubnis, meine Arbeit zuerst fertigstellen zu dürfen. Wenn dies nicht zu Hause erfolgen kann (ich könnte mich ev. täglich melden), bitte ich darum, meine Bücher und Papiere mitnehmen zu dürfen, sodass ich in der Zeit, in der ich inhaftiert bin, arbeiten kann.

Im Übrigen bin ich bereit, alle Angaben zu machen, die zur Aufklärung meines Falls erwünscht sein mögen.

Zum Schluss möchte ich nur erwähnen, dass ich nicht die Spur von der V-Bombe oder anderen militärischen Sachen weiß. Meine Arbeit hatte für den Krieg keinerlei Bedeutung und kann zu einem gewissen Grad als wissenschaftliche Sabotage bezeichnet werden, weil sie Personen vom Kriegsdienst und der Kriegsindustrie abzog."

Das Dokument ist unterzeichnet mit: „Hochachtungsvoll, Rolf Widerøe.“3. Freitag, den 25. Mai, wurde er von NEBB, wo er den gesamten Krieg über formal angestellt war, zum Gespräch einberufen. „Unter Anwesenheit von Zeugen" informierte ihn Direktor Solberg darüber, dass er das Unternehmen verlassen müsse. Dem Protokoll des Direktors zufolge soll dies vor Ort schriftlich bestätigt worden sein. Am selben Tag informierte Solberg in einem längeren Brief auch die Kriminalpolizei. ${ }^{4}$ Andererseits ist es schwer vorstellbar, dass Rolf die Untersuchungshaft überhaupt verlassen durfte, um an einem solchen Gespräch teilzunehmen. Unabhängig davon wissen wir jedoch, dass NEBB die Ausbezahlung seines Lohns unmittelbar stoppte. Das bedeutete allerdings nicht, dass der Kontakt zum Direktor und der Firma abbrach. ${ }^{5}$

\section{Verteidigung}

Der Anwalt am Höchsten Gericht, Oscar de Besche von der Anwaltskanzlei de Besche \& Co., wird zu seinem Verteidiger ernannt. Darum hat de Besche am 16. Juni formell in einem langen Brief an die Polizei gebeten. Darin schreibt er unter anderem über Rolf: „Das, was über ihn gesagt werden kann, ist wohl vor allem, dass er sich blind für sein Fach und seine Wissenschaft interessiert, ohne Rücksicht auf andere Aspekte zu nehmen, die wichtiger sein könnten. "In einem Brief der Staatsanwaltschaft vom 20. Juni erhält de Besche die Nachricht, dass sein Brief eingegangen sei und am selben Tag Haftbefehl beantragt wurde. Den für die Gerichtsverhandlung anberaumten Termin würde er beim Amtsgericht erfahren. 
Über die Rolle des Verteidigers in dem Fall findet sich im Zentralarchiv relativ wenig Dokumentation, und die Anwaltskanzlei, die heute zur Firma Arntzen de Besche gehört, hat die betreffenden Unterlagen nicht verwahrt. Rolf selbst hat im Nachhinein kaum etwas über ihn gesagt oder geschrieben - nicht, wie und warum gerade er sein Anwalt wurde, und nicht, woraus sein Beitrag bestand. Aus anderen Quellen wissen wir jedoch, dass sich auch die Widerøe-Fluggesellschaft dieses Anwalts bediente.

\section{Anklageerhebung}

Einen Monat später, am Mittwoch, den 20. Juni 1945, lag die formale Anklageerhebung vor. Sie betraf die Übertretung von $\$ 2$ der besonderen Landesverratsverordnung, die am 15. Dezember 1944 vom Parlament beschlossen worden war. In dem sogenannten Zustellungsdokument mit Antrag auf ein gerichtliches Verhör und Haftbefehl ist wortwörtlich zu lesen:

\section{Übersicht}

Fall Nr. 3418/45 AB - Dreyer

Widerøe, Rolf, geb. 11/7 1902. Wohnhaft: Melumvei 8, Røa. Derzeit: Ila Gefängnis Landesverrat.

Wird mit Anlage laut Dokumentenliste des Amtsgerichts Oslo übersandt, wobei man sich gestattet, gerichtliches Verhör und Haftbefehl für Rolf Widerøe, geb. 11/7 1902 in Oslo, wohnhaft Melumvei 8, Røa, derzeit Ila Gefängnis, zu begehren, der der Übertretung der Landesverratsverordnung vom 15. Dezember 1944, Par. 2 beschuldigt ist, dadurch, dass er

a) als Ingenieur in Deutschland in deutschen Fabriken gearbeitet hat und damit dem Feind Beistand geleistet hat,

b) verdächtigt wird, eine wichtige Erfindung betreffs der V-Bombe gemacht und diese dem Feind zur Verfügung gestellt zu haben.

Der Haftbefehl wird zu verkünden erbeten, mit Rechtsgrundlage in Strafgesetz Par. 240, vgl. 228 Pkt. 2 und 3.

Damit die Polizei in der Lage ist, bestmöglich Informationen über den Straftatbestand einzuholen, erlaubt sie sich zu ersuchen, dass die Haftdauer auf 120 Tage festgesetzt wird.

Es wird um Unterrichtung gebeten, sollte das Gericht wider Erwarten befinden, den Beschuldigten entlassen zu müssen.

Kriminalpolizei Oslo, Abteilung Landesverrat.

Oslo, den 20/6 1945.

Für den Polizeipräsidenten

Gustav B. Dreyer

$\mathrm{Pbm}$. 
Im Haftbefehl hatte gestanden: „... hat wichtige Erfindungen betreffs der V-Bombe gemacht“. In der Anklageerhebung wurde das geändert in: „... verdächtigt, eine wichtige Erfindung betreffs der V-Bombe gemacht zu haben“. Das heißt, dass die Beschäftigung mit der V-Bombe nicht mehr als eine Tatsache festgestellt, sondern zu einem Verdacht abgemildert wurde.

Der Haftbefehl basiert auf der „prov. Verordnung vom 26/2-43 \$ 2-3-45-6“, während die Anklageerhebung auf der Landesverratsverordnung vom 15. Dezember 1944, \$2, aufbaut.

\section{Verhör}

Rolf erklärte sich der Polizei gegenüber aussagebereit, auch wenn jemand, der einer Sache beschuldigt wird, nicht verpflichtet ist, sich dem Gericht gegenüber zu erklären, und auch nicht bestraft werden kann, wenn er eine unwahre Erklärung abgibt. Mehrere Verhöre fanden ohne Anwalt statt, darunter eines am 25. Juni, worüber es im Protokoll u. a. heißt:

„Der Beschuldigte behauptet, dass er durch seine Tätigkeit dem Feind keineswegs geholfen habe, dass er ihm die Hilfe ganz im Gegenteil entzogen habe, sowohl Arbeit als auch Arbeiter, die ansonsten Dienst in der Wehrmacht geleistet hätten, so vor allem zwei Ingenieure, die von der Wehrmacht freigestellt wurden, um ihm zu assistieren. Bezüglich Punkt 2 bestreitet er entschieden, überhaupt von irgendeiner Erfindung zur Verfügung des Feindes zu wissen." 6

Das Protokoll im Gerichtsbuch geht dann mit einem Vordruck von Standardformulierungen weiter, in denen an offenen Stellen der aktuelle Text eingetragen wurde (nachfolgend unterstrichen):

„Betreffs der vorliegenden Informationen wird der Beschuldigte nach billigem Ermessen des Landesverrats verdächtigt. Es wird angenommen, dass die Maßnahmen der Untersuchungshaft nach Strafprozessgesetz $₫ 240$ vgl. $\$ 223$, $\underline{2}$ und $\underline{3}$ erfolgt sind.

Schlussfolgerung: Der Beschuldigte Rolf Widerøe ist in Untersuchungshaft zu behalten, bis vom Gericht oder von der Staatsanwaltschaft anderes bestimmt wird, jedoch nicht über Montag, den 9. Juli 1945, hinaus, innerhalb dieser Zeit müssen die Voruntersuchungen abgeschlossen oder Anklage erhoben sein. Der Beschluss wird vorgelesen. Der Beschuldigte wird über die Einspruchsmöglichkeit informiert. Der Protokollkontrolleur hatte nichts anzumerken. Sitzung beendet." 
Der Inhaftierung für 120 Tage wurde also nicht zugestimmt.

\section{Entlassung}

Rolf verfasste daraufhin mehrere Erklärungen, in denen er um Entlassung bittet, darunter eine, die dem Amtsgericht am 25. Juni vorgelegt wurde. Darin verweist er auf eine Notiz, die er einen Tag nach seiner Verhaftung auf der Polizeibehörde in der Kronprinsens gate erstellt hatte, sowie auf das Verhör in Ila an den Tagen darauf:

„Aus diesen Verhören geht deutlich hervor, dass die Anschuldigungen gegen mich vollkommen unbegründet sind, offenbar ein reines Fantasieprodukt.

Für meine Arbeit in der Zeit, in der ich in Deutschland war, kann ich vollends gültige schriftliche Beweise vorlegen. Daraus geht in aller Deutlichkeit hervor, dass diese rein wissenschaftliche Arbeit nichts mit Krieg oder Kriegsindustrie zu tun hatte. Das kann von jedem Sachverständigen augenblicklich bestätigt werden. Es gibt daher, meiner Ansicht nach, keine Grundlage für die Anklageerhebung, noch weniger für die Inhaftierung. Indessen bin ich selbstverständlich an einer gründlichen polizeilichen Untersuchung interessiert, damit die Verhältnisse geklärt werden und damit ich rehabilitiert werde, hierzu ist es meiner Meinung nach jedoch nicht notwendig, mich in Haft zu belassen.

Wie gegenüber der Kriminalpolizei betont, gibt es lebenswichtige Gründe dafür, dass ich baldigst entlassen werden muss. Seit 1922 arbeite ich an einer Reihe von Erfindungen, und das Ergebnis meiner Arbeit ist in einer Reihe von Patentanträgen zusammengefasst, die jetzt eingereicht werden müssen. Wenn ich diese Patentanträge nicht baldigst beim Patentamt einreichen kann, riskiere ich, die Priorität zu verlieren und dadurch der Arbeit eines ganzen Lebens zu entgehen. Solange die Deutschen hier waren, konnte ich diese Patentanträge nicht in Norwegen einreichen, und ich war gerade mit der Ausarbeitung beschäftigt, als ich verhaftet wurde. Die Arbeit erfordert die Mitarbeit eines Patentbevollmächtigten und kann nicht im Gefängnis ausgeführt werden.

Außerdem will ich zur Geltung bringen, dass allgemeine Aspekte eine augenblickliche Freilassung gebieten. Meine wissenschaftlichen Arbeiten und Ergebnisse sind von allergrößter Bedeutung für die wissenschaftliche Forschung, und es ist von allergrößter Bedeutung, dass ich baldigst in Kontakt mit norwegischen Wissenschaftlern komme, sodass wir gemeinsam diese Arbeiten für die norwegische Wissenschaft ausnutzen können. Es wäre traurig, wenn ein noch weiter verlängerter Gefängnisaufenthalt hier in Ila wichtige Forschungswerte verspielen würde. ${ }^{\text {"7 }}$ 
In seinem ersten, auf den 5. Juli datierten und an Sachbearbeiter Gustav B. Dreyer adressierten Dokument betont der Verteidiger, dass die Erfindung ohne kriegswichtige Bedeutung war:

„Meinen Untersuchungen zufolge ist es ganz klar, dass die Erfindungen, an denen Widerøe gearbeitet hat, Instrumente für die wissenschaftliche physikalische Forschung betrafen (von wesentlicher Bedeutung für die Krebsbehandlung) und dass sie ohne jegliche Bedeutung waren, auf jeden Fall für den laufenden Krieg. Vielleicht sollte auch angemerkt werden, dass es kein neues Feld ist, in das Widerøe sich hineinbegeben hat, sondern dass es sich um dieselben Dinge handelt, mit denen er vor dem Krieg über Jahre hinweg gearbeitet hat. "8

Am Montag, den 9. Juli, wird Rolf - nach 47 Tagen Haft - aus dem Gewahrsam entlassen, allerdings mit Meldepflicht in der Polizeistation Piperviken montags und freitags. Es bestand keine Gefahr mehr für Beweisvereitelung. Der Beschluss war vom Amtsgericht Oslo gefasst und der Entlassungsbefehl am 7. Juli ausgestellt worden. ${ }^{9}$

Dann vergingen fast ein Jahr und vier Monate. Die Anzahl der Fälle von Landesverrat war enorm. Es war unsicher, wann der Fall vor Gericht kommen würde.

\section{Übersicht}

\section{Strafverfahren}

Ein Strafverfahren beginnt damit, dass jemand etwas anzeigt, das seiner Meinung nach eine strafbare Handlung ist, oder die Polizei berechtigten Grund zur Untersuchung hat, ob strafbare Umstände vorliegen, die von den Behörden verfolgt werden, oder selbst entdeckt, das dies passiert ist. (domstol.no)

\section{Verdächtiger}

Ein Verdächtiger ist eine Person, bei der die berechtigte Möglichkeit besteht, die strafbare Handlung begangen zu haben, in der ermittelt wird. Verdächtigt zu sein, führt zu eingeschränkten Rechten, man kann jedoch die Anwesenheit eines Anwalts beim Verhör fordern. (domstol.no)

\section{Anzeige erstatten}

Der juristische Ausdruck „Anzeige erstatten” bedeutet, einer öffentlichen Behörde, z. B. der Polizei, Meldung über etwas zu erstatten. (domstol.no)

\section{Verhaften}

Festnehmen, vorübergehend verhaften, bis die Ermittlungen abgeschlossen sind und das Urteil verkündet ist. (domstol.no) 


\section{Staatsanwaltschaft}

Die öffentliche Behörde, die strafbare Umstände untersucht und ahndet sowie vor den Gerichten die Strafverfahren führt. (domstol.no)

\section{Amtsgericht}

Gericht, das die erste Instanz für Strafverfahren ist. Bis 2002 wurden die Amtsgerichte entweder Land- oder Stadtgerichte genannt. (domstol.no)

\section{Untersuchungsgericht}

Untersuchungsgericht war die frühere Bezeichnung für das Amtsgericht (Stadt- und Landgericht), wenn dieses in Verbindung mit der Ermittlung Prozessschritte vornahm, z. B. Beschlüsse für Durchsuchung, Beschlagnahme, Telefonabhören oder Untersuchungshaft eines Beschuldigten. Seit einer Gesetzesänderung von 2002 wird immer die Bezeichnung Amtsgericht verwendet, unabhängig von der Funktion des Gerichts. (domstol.no)

\section{Untersuchungshaft}

Ein Beschuldigter wird inhaftiert, bevor das Urteil vorliegt, um ihn daran zu hindern, wegen Strafvermeidung zu fliehen (Fluchtgefahr), Beweise zu zerstören (Beweisvereitelung) oder neue strafbare Handlungen zu begehen (Wiederholungsgefahr). (domstol.no)

\section{Verbrechen}

Verbrechen ist eine strafbare Handlung, die zu einer Gefängnisstrafe von mehr als 3 Monaten führen kann. (domstol.no).

\section{Anklageschrift}

Eine "Anklageschrift" ist eine Beschreibung des Gesetzesverstoßes, der nach Ansicht der Staatsanwaltschaft vorliegt. (domstol.no)

\section{Sachverständige Zeugen}

Einige Zeugen können sich zu Fragen äußern, zu denen sie über spezielles Fachwissen verfügen. Sie werden als sachverständige Zeugen bezeichnet. (domstol.no)

\section{Einsetzung des Sachverständigenkomitees}

Im ersten Herbst passiert in dem Fall nicht besonders viel. Die Staatsanwaltschaft benötigte fachliche Assistenz, um zu klären, worin Rolfs Tätigkeit in Deutschland während des Krieges bestanden hatte. Das Mandat lag am 21. November vor und bestand aus zwei Teilen: Abklärung, welche Art von Arbeit Rolf ausgeführt hat. Und Beurteilung der Wichtigkeit - in der Bedeutung Kriegswichtigkeit - der ausgeführten Arbeit. ${ }^{10}$ 
Für das Komitee wurden vier Mitglieder ernannt, alles anerkannte Fachleute. Drei von ihnen kamen vom Physikalischen Institut der Universität Oslo: Egil A. Hylleraas und Harald Wergeland, beide Professoren der Theoretischen Physik, sowie Roald Tangen, Professor der Kernphysik. Wergeland und Tangen hatten mit Atom- und Kernphysik an der damaligen NTH in Trondheim gearbeitet, wo sie am Bau von Norwegens erstem Vande-Graaff-Beschleuniger beteiligt waren, ab 1942 hatten sie diese Arbeit an der Universität Oslo fortgeführt. ${ }^{11}$ Der vierte und jüngste im Bunde war der Astrophysiker und damalige Hauptmann Gunnar Randers. Hylleraas übernahm den Vorsitz. Rolf seinerseits hatte mit allen bereits früher zu tun gehabt.

Alle Mitglieder waren profilierte Widerstandskämpfer. Als die Universität im Herbst 1943 geschlossen wurde, war Tangen verhaftet worden und hatte bis August 1944 als Gefangener in Grini eingesessen. Wergeland war Mitglied der geheimen Organisation XU gewesen, ${ }^{12}$ Randers wiederum Mitglied im Technischen Ausschuss des Oberkommandos der Armee (FOTU), der norwegische Forscher und Ingenieure für die britische Militärforschung rekrutierte.

In der Empfehlung an den Polizeichef für die Ernennung hatte der Sachbearbeiter darauf aufmerksam gemacht, dass Hylleraas und Randers bereits zuvor vom Oberkommando der Armee in einem Expertenkomitee zur Beurteilung von Fragen zur Atombombe eingesetzt worden waren. Randers hatte zudem eine Sonderstellung inne, weil er bei Allied Security für Untersuchungen der deutschen Atomforschung gearbeitet hatte. Der Sachbearbeiter schrieb auch: „Bei der Besatzung Deutschlands erhielten die Alliierten volle Übersicht über Rolf Widerøes Tätigkeit in Deutschland.“ Weiterhin stellte er fest: „Die Frage zur Ausnutzung von Patentrechten sollte auch aufgegriffen werden - eventuell Sicherung dieser durch Beantragung von Patenten, wo dies nicht erfolgt ist." 13 Dann informierte er darüber, dass zwei der mitgesandten Anlagen „von Hauptmann Randers ausgeliehen sind, mit Anmerkung, dass Rolf Widerøe nicht erfahren darf, dass sie von ihm stammen". 14

\section{Der Bericht des Komitees}

Am 14. Februar 1946, nach fünfmonatiger Arbeit, lieferten die Sachverständigen ihren Bericht ab. Dieser bestand aus einem achtseitigen Dokument mit zwei Anlagen von einer beziehungsweise sechs Seiten, insgesamt 15 Seiten. Den endgültigen Text hatte der Vorsitzenden des 
Komitees, Egil Hylleraas, formuliert. ${ }^{15}$ Nachfolgend einige wichtige Abschnitte des Berichts, der adressiert war an: „Polizeibehörde Oslo, Kriminalabteilung (Landesverrat), 14. Febr. 1946“.

Zuerst wird aufgelistet, welche Unterlagen dem Komitee zugeschickt worden waren: eine 70-seitige Darstellung, die Rolf im Gefängnis geschrieben hatte, worin er seine wissenschaftliche Arbeit erklärte. Außerdem die beiden Artikel aus dem Physical Review von 1941 von dem Amerikaner Kerst, dem es erstmals gelungen war, ein funktionsfähiges Betatron zu bauen, sowie eine Liste über zehn bis zwölf verschiedene, von Rolfs Mitarbeitern und anderen deutschen Physikern verfasste Artikel. Sechs Artikel der Liste stammten von seinem Assistenten Bruno Touschek. ${ }^{16}$

Die Sachverständigen gehen historisch vor und nehmen Kersts Artikel zum Ausgangspunkt, den sie als „Hintergrund für Ingenieur Widerøes behauptete Erfindung“ ansehen. Dann wird der Vortrag „Über die technischen Probleme der Kernforschung" erwähnt, den eines der Komiteemitglieder, Tangen, an der Universität Oslo gehalten hatte - worin Bezug auf den Amerikaner genommen wird - und bei dem Rolf anwesend war und „mit Kersts Arbeit bekannt wurde“. Und das habe etwas in Gang gesetzt:

„Das hat bei ihm offensichtlich ein enormes Interesse geweckt. Widerøe hatte nämlich (nach einer Arbeit von 1928) bereits 1927-1928 versucht, einen Hochspannungsgenerator nach wesentlich den gleichen Prinzipien zu bauen im Übrigen wird behauptet, seine Idee sei bereits von 1922.“

\section{... über die Motive: Mindestens drei}

Dann geht das Komitee auf Rolfs Motive für seine fachliche Tätigkeit ein:

„Ingenieur Widerøe hat sich offensichtlich umgehend der Aufgabe angenommen, Kersts 'Betatron' nachzuahmen und möglicherweise zu verbessern. Für die Aufnahme der Tätigkeit gab es natürlich verschiedene Motive. Zweifellos hat Widerøe ein rein intellektuelles Interesse an dem Problem. Danach wollte er vermutlich, wenn möglich durch Verbesserung, eine Art Priorität als Erfinder des Betatrons wiedergewinnen. Schließlich hat er sich vermutlich erhebliche Hoffnungen auf die geschäftsmäßige Ausbeute aus patentierten Erfindungen in Verbindung mit dem Betatron gemacht. Das letzte Motiv führte auch dazu, dass er 1943 sogar ein deutsches Patent für seine mutmaßlichen Erfindungen beantragte." 
Auf Seite 2 unten geht der Bericht darauf ein, warum der Kontakt des norwegischen Physikmilieus zu Rolf während des Krieges abgebrochen wurde:

„In den Akten des Falls wird erwähnt, dass Herr Widerøe seine Erfindung 1943 mit einem der Mitglieder des Komitees (Wergeland) besprochen habe. Diese Besprechungen beschränkten sich auf einige wenige einfache Prinzipfragen über die Bewegung der Elektronen. Weder Wergeland noch andere waren sonderlich begeistert, zu viel mit Widerøe zu tun zu haben. Widerøe war interessiertes Mitglied im Physikverband, wo er im Frühjahr 1941 einen Vortrag über die Stromversorgung des Østlandet hielt, und er war treibende Kraft einer Spendenaktion für den Neustart der Verbandszeitschrift. Bei einigen Anlässen machte er indessen Äußerungen, die zeigten, dass er neben von ihm unternommenen Reisen nach Deutschland auch deutsche Sympathien hegte - oder zumindest Bewunderung. Das weckte Enttäuschung, und das trug auch dazu bei - zusammen mit der Drohung auf Kontrolle von Verbänden -, dass der Physikverband seine Tätigkeit später einstellte, bis der Krieg vorüber war. All das führte dazu, dass der Kontakt zu Widerøe endete und seine deutschen Patentansprüche von 1943 ebenso wie seine spätere Arbeit in Deutschland den Mitgliedern des Komitees unbekannt waren, bis man nach der Kapitulation von seiner Verhaftung und der Anklage gegen ihn hörte."

\section{... über das Betatron: Eigene Anlage}

Die nächsten Seiten behandeln die fachlichen Prinzipien, auf denen das Betatron aufbaut, und liefern eine Beschreibung „der experimentellen Arbeit in Hamburg". Es wird darauf hingewiesen, dass nach dem Bau des 15-meV-Betatrons „Ingenieur Widerøes behauptete Erfindungen mit rein theoretischen Vorschlägen verbunden sind, die vermutlich auf einen Beschleuniger von $30 \mathrm{meV}$ und einen anderen mit maximaler Spannung von $200 \mathrm{meV}$ abzielten“. Hier verweist das Komitee auf die ihm vorgelegte eigene Darstellung von Rolf. Eine „eingehendere Einschätzung“ sei hier „für das Gericht für gewöhnlich kaum von besonderem Interesse“, heißt es. Das Komitee nimmt sie dennoch als Anlage auf und begründet das wie folgt:

„Widerøe selbst und sein Verteidiger haben indessen versucht, seine Erfindungen als besonders bedeutungsvoll darzustellen, sogar in Bezug auf das Land. Seine Arbeiten und Ideen als Erfinder haben auch hier zu Hause beträchtliches Interesse geweckt, nicht zuletzt aufgrund des Interesses der Deutschen an seinen Projekten. 
Daher fand es das Komitee erforderlich, in einer gesonderten Anlage eine detailliertere kritische Einschätzung seiner theoretischen Vorschläge abzugeben. Es gibt auch eine Erklärung seiner Punkt für Punkt formulierten Patentbehauptungen, die sich in den Dokumenten des Falls finden."

\section{... über die Patente: Für Norwegen nicht von Interesse}

Dann geht das Komitee auf den Punkt über die Patente ein und schlussfolgert, dass es nicht erkennen könne, „dass es für Norwegen von irgendeinem Interesse sein sollte, sich Ingenieur Widerøes eventuelle Patentrechte zu sichern":

„Ingenieur Widerøes neue norwegische Patentansprüche müssen wohl als von geringerem Interesse betrachtet werden. Seine eventuellen Patentrechte in Deutschland sind selbstverständlich von den Alliierten beschlagnahmt und Eigentum der Alliierten, und es dürfte wohl höchst zweifelhaft sein, ob das Patentamt die Befugnis hat, ihm hier neue Patentrechte für dieselben Ideen zuzuteilen."

Über den Patentanspruch gegenüber Kerst gibt das Komitee an, dies könne nur ,von Fachleuten entschieden werden, nachdem die Literatur auf diesem Gebiet zugänglich geworden ist". Dennoch hat das Komitee einige Anmerkungen:

„Das Komitee betrachtet es als ein Unding, dass Außenstehende Patentrechte auf technische Details beantragen, die in Verbindung mit von anderen realisierten Erfindungen stehen und die sich durch die Arbeit verschiedener Forscher in schneller Entwicklung befinden. Zu Widerøes Entschuldigung kann nur angeführt werden, dass er sich persönlich als den eigentlichen Erfinder des Betatrons sieht und dass seine Interessen als Ingenieur einseitig dahin gehen, sein Erfindertalent finanziell und kommerziell auszunutzen.

Tatsächlich verhält es sich indessen so, dass Kerst als Erster die nötigen und hinreichenden theoretischen Grundlagen für das Betatron geklärt und auf dieser Grundlage das erste funktionsfähige Betatron konstruiert hat. Da seine Arbeit in einer der größten Physikzeitschriften publiziert wurde und zudem eine sehr erschöpfende Theorie für Elektronenbeschleunigung durch magnetische Induktion enthält, die u. a. auch eine so spezielle Sache wie die Vormagnetisierung des Steuerfeldes umfasst, sind seine Vorrechte gegenüber jeglichem Patentanspruch von anderer Seite zweifellos sehr groß. Außerdem müssen wir damit rechnen, dass die theoretischen Vorschläge von Widerøe, die von Interesse sein könnten, womöglich bereits durchdiskutiert und erprobt sind.“ 


\section{... über Rolf: Keine wissenschaftlichen Voraussetzungen}

Generell heißt es über Rolf als Person:

„Abgesehen von den Patentrechten und ihrem Wert scheint Widerøe der Meinung zu sein, dazu beitragen zu können, dem Land eine führende Stellung auf einem begrenzten Gebiet der Atomforschung einzuräumen, indem er seine Ideen zur Verfügung stellt. Vor dieser Auffassung möchte das Komitee stark warnen. Bei der Planung großer und kostbarer Apparaturen für die Atomforschung müssen alle Fortschritte auf dem Gebiet gut bekannt sein, und alle Pläne müssen unter theoretischen und praktischen Gesichtspunkten genau geprüft werden. Das kann nur durch erfahrene Physiker erfolgen, wie es auch in allen führenden Ländern geschieht, nicht zuletzt in Amerika. Ingenieur Widerøe verfügt nicht über die nötigen wissenschaftlichen Voraussetzungen, eine solche Arbeit zu leiten.

Ingenieur Widerøe verfügt über eine üppige Erfinderfantasie, jedoch hat er nicht die Fähigkeit gezeigt, seine Ideen hinreichend klar und theoretisch unangreifbar zu erörtern. Sein misslungener Versuch 1928 beruhte auf fehlender theoretischer Einsicht, und diese Einsicht kam erst nach Kersts Arbeit von 1941. Aber auch nach Kenntnis dieser rationellen Grundlage sind seine theoretischen Auslegungen sehr umständlich und unklar, obwohl er - wie es aussieht - in der Bearbeitung wichtige Unterstützung von deutschen Mitarbeitern erhalten hat.

Seine Ideen sind oft alternativ (anders sind sie auch nicht gemeint), sodass die eine die andere ausschließt. Das Komitee muss es als zweifelhaft betrachten, dass er Aussicht darauf hat, seine Ideen eigenständig zu den zweckmäßigen Lösungen für das Betatron zu führen. Sein wichtigster Vorschlag dürfte die Vormagnetisierung des Steuerfeldes sein. Andererseits kommt er in seinen Erörterungen über den Nutzen stabilisierender elektrischer und magnetischer Linsen zu gänzlich irreführenden Ergebnissen."

\section{... über die Schuldfrage: Will nichts sagen, aber ...}

Auf der vorletzten Seite schreibt das Komitee, dass es mit der Schuldfrage nichts zu tun haben wolle:

„Das Komitee wünscht selbstverständlich, den geringstmöglichen Einfluss auf die Entscheidung der Schuldfrage zu haben, die seiner Meinung nach ausgehend von beschlossenen juristischen und allgemeinmenschlichen Gesichtspunkten entschieden werden muss, die nur das Gericht beherrscht. Das Komitee sieht sich indessen verpflichtet, mit den Angaben und der Hilfe beizutragen, die es leisten kann." 


\section{... über die V-Bombe: Hat nichts mit den V2-Raketen zu tun}

Im nächsten Abschnitt wird konstatiert, dass das Komitee keinerlei Verbindung zur V-Bombe gefunden hat:

„Obwohl ein Mitglied des Komitees (Randers) an den Ermittlungen in Deutschland beteiligt war, gibt es keine Informationen, die darauf hindeuten, dass Ingenieur Widerøe irgendeine Verbindung zur Arbeit an den V-Bomben hatte. Das Komitee findet es auch natürlich, zu glauben, dass die Realisierung der Pläne für den Bau von Betatronen seine komplette Zeit des DeutschlandAufenthalts in Anspruch genommen hat."

\section{... über Schiebolds Todesstrahlen: Aussage gegen Aussage}

Ob Rolf „dem Feind Beistand geleistet habe“, sei eine rechtlich-juristische Frage, schreibt das Komitee, fügt jedoch hinzu:

„Es ist klar, dass Schiebolds fantastische Ideen von 'Todesstrahlen' (zur Anwendung gegen Flugzeuge) eine mitwirkende Ursache dafür waren, dass sich die Deutschen Widerøe gesichert haben. Daneben hat der Wunsch, mit den Amerikanern auf einem neuen Gebiet zu wetteifern, das vielleicht Bedeutung für die Atomphysik haben könnte und dadurch auf Umwegen möglicherweise auch für Atomwaffen, eine gewisse Rolle gespielt.

Dagegen steht Ingenieur Widerøes Behauptung, dass er erst später von Schiebolds Plänen gehört habe und sich die ganze Zeit über im Klaren war, dass das Betatron keine kriegswichtige Bedeutung habe - sowie der faktische Umstand, dass seine Arbeit in Deutschland (wir gehen davon aus, dass sie sich auf das Betatron beschränkte) für die Deutschen von keinem kriegswichtigen Nutzen war. Eine andere Sache ist natürlich, wie groß die Gefahr war, dass Widerøe solche Arbeit zugewiesen würde, und inwieweit er diese Gefahr hinreichend bedacht hat."

\section{... über den Hintergrund: Nicht von Bedeutung}

Gegen Ende der Stellungnahme wird das aufgegriffen, was Rolf während des Krieges nach Deutschland geführt habe. Das Komitee gibt Rolfs Erklärung wieder und verweist darauf, dass dies zu den Fragen gehöre, 
die nach Meinung des Komitees außerhalb seines Mandats liegen. Einige Anmerkungen gibt es dennoch:

„Widerøe behauptet, unter Zwang nach Deutschland gebracht worden zu sein. Die Frage nach der Richtigkeit dieser Behauptung betrachtet das Komitee als irrelevant. Wichtiger ist Widerøes Reaktion bei der Ankunft in Deutschland, und hier scheint er zumindest nur schwache Einsprüche erhoben und sich auf jeden Fall nicht geweigert zu haben, zu arbeiten. Ganz im Gegenteil hat er für sich sehr günstige Verträge geschaffen, die laut Unterlagen des Falls die Ausbezahlung eines Betrags von 38.000 Reichsmark, in Norwegischen Kronen vermutlich des doppelten Betrages, mit sich führten. Späteren Angaben Widerøes zufolge wurden ihm insgesamt rund 150.000 Kronen ausbezahlt.

Aus Widerøes Tagebuch für 1943 geht hervor, dass er lebhaft mit einem deutschen Ingenieur Sommerfeld korrespondiert und dass er im Frühjahr und Sommer wiederholte Male Reisen nach Deutschland unternommen hat, vermutlich um seine Patentanträge vorzubereiten und zu regeln. Dadurch musste er doch zwangsläufig ins Visier der Deutschen geraten. Auf der anderen Seite zeigt dies auch, dass er - im Gegensatz zu anderen - der Ansicht gewesen sein muss, dass deutsche Patentrechte einen besonderen Zukunftswert haben. Mit anderen Worten, er muss gehofft, gewünscht oder erwartet haben, dass Deutschland durch das ein oder andere Wunder dennoch siegen würde."

\section{... über die Gesinnung: Unnational}

\section{Die Stellungnahme wird wie folgt beendet:}

„Das Komitee muss seine Gesinnung daher als unnational betrachten. Ausgehend von seiner Auffassung vom zivil-ökonomischen Wert der Leistungen von Ingenieur Widerøe hält es die Höhe der ausbezahlten Beträge für stark kriegsbetont. Egal ob diese Beträge ohne Weiteres vom deutschen Staat ausbezahlt oder in Form von Lizenzabgaben getarnt wurden, muss er diese daher als Kriegsprofit betrachten.

Während der Behandlung des Falls hat Ingenieur Widerøe, in Verbindung mit Patentansprüchen, dem Komitee einen Bericht über neue Erfindungen vorgelegt. Nach all der Arbeit, die das Komitee für Widerøes Fall geopfert hat, kann es keine Zeit mehr für die Überprüfung dieser neuen Projekte entbehren. Für das Gericht ist dies auch nicht von Interesse, da es sich um neue Arbeiten handelt, die keine andere Verbindung zu seiner Arbeit in Deutschland haben, als dass sie sich mit verwandten Problemen befassen.

Das Komitee hat aus verschiedenen Gründen viel Arbeit investiert, um zu der möglichst richtigen Einschätzung des fachlichen Werts von Ingenieur Widerøes Arbeiten zu kommen, und es hat diese Fragen auch mit Professor 
Trumpy und Ingenieur Dahl, Bergen, besprochen. Das Komitee ist indessen der Auffassung, dass der technische und fachliche Wert seiner Arbeiten keinen Einfluss auf die Beurteilung seines Falls haben sollte, sondern dass diese auf Grundlage rein juristischer Gesichtspunkte erfolgen muss. Daher ist es auch der Meinung, dass weitere fachliche Diskussionen in diesem Zusammenhang überflüssig sind.“

Das Dokument ist unterzeichnet mit: „Blindern V. Aker, 14. Februar 1946“ und unterschrieben von allen vier Komiteemitgliedern: Egil A. Hylleraas, Gunnar Randers, Roald Tangen und Harald Wergeland. Der Stellungnahme sind zwei Anlagen hinzugefügt. Anlage 1 ist die Liste über die Artikel, auf die hingewiesen wird. Anlage 2 ist ein sechsseitiges Dokument mit dem Titel „Betr. 'Strahlentransformator'“, verfasst und unterzeichnet von den Komiteemitgliedern.

\section{Die Schlussfolgerung des Komitees}

Das Sachverständigenkomitee schlussfolgerte damit, dass nichts bekannt sei, was darauf hindeute, dass Rolfs Tätigkeit eine Verbindung zu den V2-Raketen gehabt hatte. Er habe ausschließlich am Betatron gearbeitet, und das habe für die Deutschen keine kriegswichtige Bedeutung gehabt. Seine fachlichen Qualifikationen zog das Komitee stark in Zweifel.

Der Verteidiger ging die Evaluierung der Sachverständigen Punkt für Punkt durch. In einem umfangreichen Dokument an die Polizeibehörde konstatiert er, nicht in irgendeine Diskussion über Rolfs fachliche Qualifikationen einsteigen zu wollen. Er wolle lediglich erwähnen, dass es ihm vorkomme, ,als ergreife das Komitee unnötig stark Partei für den amerikanischen Erfinder Kerst". Und wie groß die Bewunderung des Komitees für diesen Erfinder auch sein möge, so halte er „es für vollkommen unrichtig, Widerøe als einen Außenstehenden auf diesem Gebiet zu charakterisieren, mit der etwas odiösen Bedeutung, die diesem Wort gern beigemessen wird“. Und er fügt hinzu:

"Jeder darf im Übrigen seine eigene Auffassung von Ingenieur Widerøes Qualifikationen haben, für mich fällt es sehr stark ins Gewicht, dass die globale Firma Brown Boveri in der Schweiz mit ihm zusammenarbeiten möchte und dass sein Name in den meisten modernen Werken über Atomphysik genannt ist. Es ist zumindest deutlich, dass es andere Meinungen als die des Komitees darüber gibt, inwieweit es denkbar ist, dass er brauchbare Resultate erzielt." 17 
Weiter schreibt er, dass Ingenieur Sommerfeld, mit dem Rolf nach Behauptung des Komitees „lebhaft korrespondiert“ habe, „glühender Antifaschist“ sei, dessen „Vater, einer der führenden Physiker Deutschlands, aufgrund von Antifaschismus von der Universität geworfen worden“"war. Sommerfeld jr. war sowohl Ingenieur als auch Patentanwalt, und durch ihn habe Rolf „seine Patentanmeldungen zum Einsatz durch Brown Boveri durcharbeiten " können.

Im Hinblick auf den wichtigsten Punkt, die Frage, inwieweit Rolfs Arbeit in Deutschland Bedeutung für den Krieg hatte, „sollten die Aussagen des Komitees klar und deutlich sein": Es war nichts erkennbar, was darauf hindeutete, dass er eine Verbindung zur Arbeit an der V-Bombe hatte, und seine Arbeit habe für die Deutschen keinen kriegswichtigen Nutzen gehabt.

Der Verteidiger konstatiert:

„Das Komitee erkennt, soweit ersichtlich, die Tatsache an, dass Widerøe im Herbst 1943 unter Zwang nach Deutschland gebracht wurde, und jeder, der seine Verbindung an Haus und Familie kennt, wird sich auch im Klaren darüber sein, dass er niemals freiwillig abgereist wäre."

Die Anklage auf fehlende nationale Gesinnung weist er direkt zurück. Rolf habe dem Feind in keiner strafbaren Weise Beistand geleistet:

„Erstens war die Arbeit vollkommen ungefährlich und zweitens ist das, was ausgeführt wurde, in hohem Maße unter Einfluss einer Zwangssituation erfolgt. Das kann nicht Gegenstand irgendeiner Art von Strafe sein. (...) Widerøe hat gegenüber dem Nationalsozialismus, dessen Gegner er immer war, stets klar Position bezogen. Unterdessen ist es denkbar, dass er seine Bewunderung für Zweige der deutschen Wissenschaft geäußert hat, was in der Zeit des Krieges sowohl unnötig als auch dumm war, strafbar ist es jedoch nicht."

\section{Diverse Verhöre}

„Kein NS-Mitglied“ steht zusammen mit Rolfs Name und Angaben zur Person im Protokoll des Verhörs im Büro des Kriminalchefs am 15. März. Darin erklärt sich Rolf zur Studienreise nach Deutschland im Herbst 1941 zusammen mit einer Gruppe norwegischer Ingenieure und dem deutschen Direktor Schwartz, den er von seiner Zeit bei NEBB kannte. Erneut 
erwähnt er, dass sein Bruder im selben Jahr inhaftiert und zu zehn Jahren Zuchthaus verurteilt worden war:

„Durch Direktor Schwartz, der ein Bekannter Todts war, ersuchte ich bei Reichsminister Todt um Begnadigung. Um dieses Ersuchen empfehlen zu können, meinte Schwartz, dass man auf etwas verweisen müsse, dass ich Deutschland gegenüber günstig gestimmt sei. " 18

Dann gibt er etwas bekannt, worauf er in späteren Interviews nie wieder zurückkommt:

„Nach der Studienreise nach Deutschland hatte ich einen komplett sachlichen Artikel für das Teknisk Ukeblad geschrieben, Schwartz bat mich jedoch, ihn ein wenig zu verändern. Ich schrieb ihn dann so um, dass einige Sätze so gedeutet werden konnten, dass ich Deutschland gegenüber wohlwollend gestimmt war.

Auf das Gnadengesuch erhielt ich nie eine Antwort, ich erfuhr lediglich, dass es abgelehnt wurde.

In diesem Zusammenhang bezahlte ich auch 80 Kronen an NSH. Ob dieser Betrag aber bei Den Norske Legion angekommen ist, entzieht sich meiner Kenntnis."

Unterdessen hat der Prozess um seine Anstellung bei Brown Boveri begonnen. Rolf ist zu Gesprächen in die Schweiz gereist, und am 24. Mai bestätigt das Unternehmen in einem Brief, dass Rolf ab 1. August angestellt sei. Der Brief wird zur Dokumentation an die Polizei übergeben. ${ }^{19} \mathrm{Im}$ Juni wendet sich dann das Außenministerium an die Polizei. Es war von seinen Mitarbeitern in der Schweiz kontaktiert worden, die Wind davon bekommen hatten, dass sich der norwegische Ingenieur Widerøe während des Krieges in Deutschland aufgehalten hatte und an „speziellen Aufgaben" gearbeitet habe; sie baten, darüber auf dem Laufenden gehalten zu werden. ${ }^{20}$

In Verbindung mit Rolfs Reise in die Schweiz schickt der Verteidiger ein Schreiben an die Staatsanwaltschaft und erinnert daran, dass Brown Boveri es „von größtem Interesse fand, baldigst" mit der Konstruktion seines „Strahlentransformators für die Krebsbehandlung" zu beginnen. Er verweist auf Informationen darüber, dass Siemens, die zuvor $90 \%$ des Bedarfs an Röntgenapparaten geliefert hatte, jetzt aufgrund der Umstände nur rund fünf Prozent liefern könne. Daher eile es, dass Rolf anfange. Zudem legt er Auszüge aus der Korrespondenz zwischen NEBB und dem Schweizer Unternehmen vom Frühjahr 1943 und darüber hinaus bei, 
„die deutlich zeigen und bestätigen, worauf zuvor aufmerksam gemacht worden war, dass Widerøe mit dem Schweizer Unternehmen in Kontakt stand, bevor er 1943 nach Deutschland kam, und es somit nicht im Sinne gehabt habe, seine Rechte in Deutschland auszunutzen“. In einem Brief von NEBB an den Anwalt wird bestätigt, dass „Dr. Widerøe hinsichtlich einer Zusammenarbeit betreffs seiner Erfindung bereits 1942 Kontakt zu BBC aufnahm". ${ }^{21}$

Am 4. Juli ist Rolf erneut zum Verhör beim Polizeibevollmächtigten Dreyer. Die Staatsanwaltschaft ist noch immer damit beschäftigt herauszufinden, ob es irgendeinen Zusammenhang mit der deutschen Waffenforschung gibt. Im Protokoll heißt es:

„Der Strahlentransformator hatte für Studien betreffs der Atombombenforschung keine Bedeutung. Die Erkenntnisse, die man daraus bezüglich der Atomspaltung gewinnen konnte, wären ohne jegliche praktische Bedeutung. Der Verhörte besprach das auch mit einigen Wissenschaftlern, die er in Hamburg traf und die an Untersuchungen der Atomspaltung arbeiteten, Dr. Suess und Professor Harnack, und diese bestätigten die Auffassung des Verhörten, ebenso Dr. Jensen. “22

Das nächste Thema waren Lohn und die finanzielle Situation:

„Die Einnahmen des Verhörten waren so geregelt, dass sein Lohn von NEBB, 17.750 Kronen, hier (Norwegen) der Familie ausbezahlt wurde. In Deutschland erhielt er ca. 500 RM pro Monat + Reisespesen."

Es gab auch eine Diskussion rund um die Besteuerung des Geldes, das ihm für Patentrechte ausbezahlt worden war, und Verhandlungen mit BBC in der Schweiz im Frühjahr und Sommer 1943, damit diese durch die Schweiz in englischsprachigen Ländern angemeldet werden konnten. Diese Möglichkeit fiel weg, als die Deutschen die Patente beschlagnahmten, was nach Rolfs Ansicht deren Wert beträchtlich minderte.

Dann kommt er noch einmal auf seinen Bruder zurück und bezieht jetzt auch Theodor Hollnack ein, den Mann, der als Bindeglied zwischen ihm und der Luftwaffe fungiert hatte:

„Der Verhörte erklärte, dass er in Deutschland mehrfach seinen Bruder besuchen durfte. Als es ihm schlecht ging, gelang es Hollnack, ihn in ein besseres Gefängnis verlegen zu lassen. Hier besuchten ihn auch Hollnack und Rolf W und erwirkten, dass er besonders gut behandelt wurde." 
Das Gnadengesuch für Viggo „wurde im Februar 1945 gewährt, kam aber insofern zu spät, da der Bruder bereits von den Amerikanern befreit worden war", heißt es weiter, und ganz zum Schluss ist zu lesen:

„Der Verhörte möchte hinzufügen, dass die Deutschen während der Verhandlungen in Berlin im Oktober 1943 auch versprachen, einige der verhafteten Funktionäre von NEBB freizulassen. Von ca. 20, die versprochen wurden freizulassen, wurden zwei freigelassen."

Am 6. Juli sendet der Verteidiger einen neuen Brief, in dem er argumentiert, dass der von Rolf einzuziehende Betrag 100.000 Kronen nicht überschreiten dürfe. Seiner Meinung nach müsse der Fall durch eine solche „Einziehung einer Geldbuße“ entschieden „und eine Anklage im Übrigen unterlassen“ werden:

„Ich glaube, das ist ein typischer Fall, der auf diese Weise entschieden werden muss. Wenn Widerøe in eine unglückliche Situation geraten ist, gründet das lediglich in einseitigen wissenschaftlichen Interessen und der Liebe zu seinem Bruder. Es war bestimmt nie seine Absicht, Verräter oder Verbrecher zu sein. Er hat seine Strafe sicher bereits mehr als hinreichend gehabt. Und ich glaube, er kann auch in der Zukunft nützlich sein. “23

Auch eine Erklärung des Bruders kann hineingespielt haben. Sie war an den Sachbearbeiter, den Polizeibevollmächtigten Dreyer, gerichtet. Darin wird darauf hingewiesen, dass Anwalt de Besche Viggo auf den Wunsch der Polizei aufmerksam gemacht hatte, ihn in Verbindung mit dem Fall des Bruders zu verhören. Viggo wollte am Tag darauf nach Stockholm, um seine Arbeit bei der Fluggesellschaft SAS aufzunehmen, und daher eine schriftliche Erklärung abgeben, anstatt persönlich vorstellig zu werden. Sollte dies nicht genügen, könnten sie ihn an der angegebenen Adresse erreichen. In der Erklärung fanden sich Informationen über seine Situation während des Krieges und Rolfs Verhalten diesbezüglich:

„Ich wurde im Mai 1941 verhaftet, im November zu zehn Jahren Zuchthaus verurteilt und im Januar 1942 nach Hamburg gebracht. Später nach Rendsburg verlegt, wo mich mein Bruder im Herbst ' 43 besuchte. Da erzählte er, dass er zwangsentlassen worden war, um in einer Fabrik für Hochspannungsanlagen in Hamburg zu arbeiten.

Später wurde ich nach Bützow verlegt, wo die Gegebenheiten sehr schlecht waren. Ich hatte Diphtherie und bekam Bronchitis und nahm bis auf 47 Kilo ab (Normalgewicht 85 Kilo). Auch hier besuchte mich mein Bruder und ver- 
suchte - über den Gefängnisdirektor - mir draußen Arbeit zu verschaffen, da mich das Zellenleben fertig machte.

Kurz darauf wurde ich in ein Arbeitslager in Dieburg gebracht, wo die Gegebenheiten bedeutend besser waren und wo Zuchthausgefangene, normalerweise, nicht sein durften.

Nach einem Besuch meines Bruders im Sommer '44, wo er und ein Deutscher namens Hollnack mit dem Lagerchef sprachen, bekam ich Arbeit auf einem großen Hof und rappelte mich wieder auf.

Ich wurde auch Vertrauensmann für sämtliche Skandinavier im Lager und konnte auf diese Weise meinen Kameraden helfen. Später erhielten wir sogar die Erlaubnis, Pakete zu empfangen.

Wurde am 26. März 1945 von den Amerikanern befreit.

Die Hilfe meines Bruders, die u. a. in der Verlegung nach Dieburg und Arbeit im Freien resultierte, hat sicher dazu geführt, dass ich diese vier Jahre in Gefangenschaft überstanden habe.

Aufgrund von Eingesperrt-Sein, Krankheit und Unterernährung war meine Gesundheit ab Herbst '43 sehr schlecht. “24

Diese Erklärung, die entstand, als Viggo auf dem Weg zu einer neuen Arbeitsstelle in Stockholm war und daher nicht persönlich zum Verhör erscheinen konnte, kann ein Proformaschreiben gewesen sein, eine notwendige Geste von Bruder zu Bruder, die angesichts der Situation und ohne tief empfundene Absicht erfolgte. Es kann aber auch tiefer Ernst sein. Allein die beiden wussten, was sich hinter den Worten verbarg. Es ist auch nicht bekannt, ob Rolf das Dokument jemals gelesen hat oder davon wusste. Unbekannt ist ebenso, wie es überhaupt zustande kam. Ein vorstellbares Szenario ist, das Rolf dachte: „Ich brauche eine formelle Erklärung von Viggo, in der er bestätigt, dass ich ihm geholfen habe. Das wird meine Position stärken." Und dann hat er Viggo durch den Verteidiger dazu gebracht, die nötigen Zeilen zu schreiben. Oder der Verteidiger hat sie selbst formuliert. Oder ein anderes Szenario, in dem Viggo dachte: „Rolf braucht jetzt meine Hilfe, ich muss bestätigen, dass sein Einsatz für mich entscheidend war. "Und daraufhin hat er die Erklärung verfasst und eingesandt.

Am 31. Juli ist Viggo zurück in Oslo und wird an der Victoria Terrasse vorstellig. „Dem Zeugen wurde sein Brief vom 8. Juli 1946 an den Polizeibevollmächtigten Dreyer vorgelegt, vorgelesen und von ihm als seine polizeiliche Erklärung angenommen. "25 


\section{Verzicht auf Hauptklage}

Was nun? Mehr als ein Jahr ist vergangen. Die Sachverständigen haben ihren Bericht vorgelegt. Ihre Stellungnahme ist ein wichtiger Beitrag für die Entscheidung der Staatsanwaltschaft, ob Klage erhoben werden soll. Der Verteidiger hat seinen Kommentar eingereicht. Rolf hat eine Erklärung abgegeben. Zeugen haben ausgesagt.

Was passiert? Die Staatsanwaltschaft verzichtet gemäß der Schlussfolgerung der Sachverständigen auf die ernste Hauptklage der Anklageerhebung, die darauf hinauslief, „dem Feind Beistand geleistet zu haben“. Beim zweiten Punkt, der V-Bombe, hat das Komitee festgestellt, dass Rolf seine gesamte Zeit in Deutschland auf die Arbeit am Betatron verwendet hatte; und die Bombe wird nicht mehr erwähnt. Auch hier folgt die Staatsanwaltschaft dem Vorschlag des Komitees.

Für den Umgang mit dem, was von der Anklageerhebung noch übrig ist, gibt es zwei Möglichkeiten: Die Staatsanwaltschaft kann den Fall vor Gericht bringen - entweder als Geständnis-Fall (wenn der Angeklagte die Schuld anerkennt) oder als Hauptverhandlung vor dem Amtsgericht. Dann müsste die Polizei oder der Staatsanwalt Anklage erheben. Die Staatsanwaltschaft kann als Reaktion aber auch eine Geldstrafe festlegen, das heißt ein Bußgeld verhängen - eine Variante, die häufig bei kleineren Strafverfahren Anwendung fand.

\section{Keine Anklage}

Die Staatsanwaltschaft entscheidet sich für Letztgenanntes, verkündet den Beschluss, dass das Ganze in einer Geldstrafe mündet. Einer der möglichen Gründe ist sehr einfach: Die Reihe der Fälle von Landesverrat war lang. Ein anderer möglicher Grund ist, dass sich der mit dem Widerøe-Fall betraute Sachbearbeiter einbrachte. Hinzu kamen selbstverständlich die Realitäten in der Angelegenheit, derer er beschuldigt war, die nunmehr zusammengeschrumpft waren. Auf jeden Fall gab es keinen Prozess im üblichen Sinne.

Rein praktisch wird von einem Polizeianwalt oder einem Staatsanwalt ein Bußgeldbescheid ausgestellt und dem Angeklagten per Post zugesandt. Der Bußgeldbescheid beinhaltet eine Übersicht der Gesetzesbestimmungen, gegen die der Betreffende verstoßen hat, sowie der ausgeführten Taten. Angegeben wird darin auch die Höhe des Bußgeldes sowie der Gefängnis- 
strafe, sollte das Bußgeld nicht bezahlt werden. Wird der Bußgeldbescheid angenommen, ist der Fall abgeschlossen.

Der Sachbearbeiter war in diesem Fall wie ein Joker hinzugekommen. In einem Brief an die Staatsanwaltschaft vom 11. Juli 1946 hatte er seine Vorschläge zu den Hauptpunkten des Bußgeldbescheids dargelegt. Er war der Meinung, die Sache sei mittlerweile viel zu weit gegangen, weshalb er eine persönliche Nachricht beilegte, berichtet Tor Brustad. Darin kommentierte er unter anderem die Höhe des einzuziehenden Betrags. Während der Arbeit an dem Fall war nämlich bekannt geworden, dass Rolf für die Nutzung seiner Patente eine Vergütung von 140.000 Kronen erhalten hatte. Der Sachbearbeiter schlug jedoch vor, dass sich der einzuziehende Betrag nur auf 120.000 Kronen belaufen solle, da 20.000 Kronen seiner Ansicht nach als Ausgaben abgezogen werden sollten. Außerdem plädierte er dafür, sowohl den Punkt bezüglich des Verlusts der Bürgerrechte als auch das Bußgeld ganz zu streichen. ${ }^{26}$

Professor Brustad zufolge lohnt es, sich die Begründung des Sachbearbeiters zu merken:

„Meine möglicherweise etwas milde Einstellung gegenüber Widerøe ist in erster Linie dem Umstand geschuldet, dass er meiner Meinung nach zu den wertvollen Menschen gehört, an denen man festhalten sollte. Eine zu harte Strafe zum jetzigen Zeitpunkt könnte möglicherweise zur Emigration führen - zumindest zu einer Arbeit im Ausland, womit uns nationalökonomisch nicht gedient wäre. Die erste ernste Anklage ist jetzt auch weggefallen."

In einer Mitteilung an den Sachbearbeiter kommentiert der Kriminalchef am 22. Juli Rolfs Kontakt zu dem Deutschen Sommerfeld. Er weist dabei auf Folgendes hin: Wäre diese ganze Familie so antifaschistisch gewesen, wie Rolf es darstellen will, wäre sie automatisch unter Kontrolle gestellt worden, und unabhängig davon hätte der Briefwechsel mit dem Ausland nicht ohne Kontrolle erfolgen können. Deshalb müsse man davon ausgehen, dass der Inhalt an den deutschen Sicherheitsdienst berichtet wurde. ${ }^{27}$

Er empfahl, Rolfs Notizbücher und privaten Papiere genau durchzugehen und von Rolf eine Erklärung zu den verschiedenen Notizen zu verlangen, die er im Zeitraum 1943 bis 1944 gemacht hatte.

Sollte das Ergebnis daraus ihm zum Vorteil gereichen, müsse der Bußgeldbescheid über 140.000 Kronen sowie einem Bußgeld in Höhe von 5000 Kronen dennoch bestehen bleiben. Sollte aus den neuen Erklärungen jedoch hervorgehen, dass die Zusammenarbeit mit öffentlichen deutschen Einrichtungen enger war, müsse der ganze Fall neu aufgenommen werden, 
inklusive Verhören jener Deutschen, die interniert oder in Deutschland verhaftet waren.

Dann vergehen knapp zwei Monate. Am 14. September sendet der Sachbearbeiter den Fall erneut an den Kriminalchef und schreibt: „Mein Vorschlag beläuft sich auf ein Bußgeld in Höhe von 5000 Kronen und den Einzug von 120.000 Kronen, da es mir angemessen erscheint, dass ihm der einzuziehende Betrag um 20.000 Kronen reduziert wird, die er in Deutschland 'zum Erwerb des Einkommens' hatte. " ${ }^{28}$ Am 5. Oktober wird Rolf erneut zum Verhör einbestellt. Jetzt dreht es sich um das Geld für die Kriegsfreiwilligen. In dem Bericht steht: Der „Verhörte (...) leugnet jegliche Kenntnis davon, dass er im Sommer 1941 an die Freiwilligen-Legion Norwegen $100 \mathrm{Kr}$ einbezahlt habe“. Erklärt wird der Zusammenhang wie folgt:

„Die zu einem früheren Zeitpunkt erwähnte Gruppenreise von Ingenieuren nach Deutschland begann im September 1941. Der Verhörte erhielt vermutlich Anfang 1941 Kenntnis von der Reise. Schwartz im RK hatte für die Teilnehmer der Tour eine Regelung veranlasst, sodass jeder von ihnen einen Betrag in Norwegischen Kronen an ihn einbezahlen konnte. Ihnen würde dann in Deutschland, entsprechend dem hier einbezahlten Betrag, Taschengeld ausbezahlt, vermutlich ca. 100 RM. Die einzige für den Verhörten denkbare Möglichkeit ist, dass Schwartz im Namen des Verhörten 100 Kronen an die Freiwilligen-Legion Norwegen einbezahlt habe. ${ }^{\text {229 }}$

Es vergehen erneut anderthalb Monate, dann aber ist die Staatsanwaltschaft der Ansicht, dass es der Mühe nicht wert sei, die Sache näher zu untersuchen oder weitere Zeugen einzubestellen. Der Bußgeldbescheid wird ausgestellt.

\section{Übersicht}

Verteidiger

Ein Anwalt, der einem Beschuldigten oder Angeklagten beisteht. (domstol.no)

\section{Richterliche Verfügung}

Eine Entscheidung des Gerichts, die weder ein Urteil noch ein Beschluss ist. Eine Entscheidung, die darauf hinausläuft, einen Fall abzuweisen oder aufzuheben, ist eine richterliche Verfügung. Das Gericht trifft Entscheidungen bei Urteilen, richterlichen Verfügungen oder Beschlüssen. Richterliche Verfügungen müssen begründet und können durch reguläre Rechtsmittel angegriffen werden. (domstol.no) 
Anklage

Anklage (oft Anklageschrift genannt) ist das Anklagedokument der Staatsanwaltschaft, das in Strafsachen vor Gericht präsentiert wird. Die Anklageschrift benennt das Thema, zu dem das Gericht Stellung beziehen soll, und bildet zusammen mit den vorgelegten Beweisen das, worauf das Gericht seine Entscheidung gründet. (domstol.no)

\section{Angeklagter}

Bezeichnung einer Person, gegen die die Staatsanwaltschaft eine Anklageschrift erhoben hat. (domstol.no)

\section{Hauptverhandlung}

Mündliche Verhandlungen im Gericht, die nach Abschluss der vorbereitenden Sachbearbeitung sowohl bei Zivilverfahren als auch bei Strafverfahren direkt vor dem urteilenden Gericht stattfinden. Nach Beendigung der Hauptverhandlung wird das Urteil verkündet. (domstol.no)

\section{Urteil}

Entscheidung des Gerichts, die den Fall beendet. In einem Zivilverfahren wird über die geäußerte Forderung entschieden. In einem Strafverfahren wird entschieden, ob der Angeklagte oder Beschuldigte einer strafbaren Handlung schuldig ist und welche Strafe er in diesem Fall erhalten soll. (domstol.no)

\section{Bußgeldbescheid}

Ein Dokument, das vor allem bei geringeren Strafverfahren angewendet und das von der Staatsanwaltschaft ausgestellt wird. (domstol.no)

\section{Bußgeldbescheid}

Ist die Polizei der Meinung, dass eine Handlung nur mit einem Bußgeld bestraft werden soll, stellt sie einen sogenannten Bußgeldbescheid aus. Ein Bußgeldbescheid ist ein Angebot der Polizei an den Beschuldigten, den Fall durch Zahlung eines Bußgeldes zu klären. Erkennt der Beschuldigte den Bußgeldbescheid nicht an, wird der Fall zur Entscheidung an das Gericht übergeben. (kildenett.no)

\section{Bußgeldbescheid}

Ist die Staatsanwaltschaft der Meinung, dass ein Fall mittels Bußgeld oder Einzugsbetrag - oder beidem - entschieden werden soll, kann sie einen Bußgeldbescheid erstellen, anstatt Anklage zu erheben. Der Bußgeldbescheid soll eine Beschreibung der strafbaren Handlung beinhalten, der eine Person verdächtigt wird, sowie eine Beschreibung des übertretenen Strafgebots sowie des Bußgeldes, das dem Betreffenden für die Handlung auferlegt werden soll, und welcher Betrag eventuell einzuziehen gefordert wird. Der Beschuldigte kann selbst entscheiden, ob er den Bußgeldbescheid akzeptieren will. (domstol. no) 
Vereinfachter Bußgeldbescheid

Vor Ort Erteilung eines Bußgelds nach festgelegten Sätzen für geringere Vergehen im Straßenverkehr. (domstol.no)

\section{Akzeptanz des Bußgeldbescheids}

Rolf erhält den Bußgeldbescheid. Akzeptiert ihn. Unterschreibt ihn. Wohlwissend, dass ein vom Beschuldigten angenommener Bußgeldbescheid die gleiche juristische Wirkung hat wie ein Urteil. „Bußgeldbescheid“ bedeutet, dass man die Strafe ohne Prozess akzeptiert. Formal geschah das durch seine Unterschrift bei der Polizeibehörde Oslo am 2. November 1946.

In dem Dokument - Formular „LV. Nr. 14. Bußgeldbescheid und beschränkter Rechtsverlust, Einzug und Erstattung“ - standen ganz oben die fatalen Worte über die Strafe bei Landesverrat:

\section{Übersicht}

\section{BUSSGELDBESCHEID}

Name: Rolf Widerøe, geboren: 11.7.1902, wohnhaft: Melumvn 8, Røa, wird hiermit die Strafe nach der provisorischen Verordnung vom 15. Dezember 1944 $\S 3$, vgl. § $2 \mathrm{Nr}$. 4 vorgelegt.

Dann folgten der Hinweis auf die geltenden Paragrafen, die Auflistung der drei Punkte der Anschuldigung sowie zum Schluss das Strafmaß:

\section{Die Verordnungen in § 2 legen fest:}

Nach dieser Verordnung kann bestraft werden:

(Die Punkte 1, 2 und 3 sind durchgestrichen.)

4. Derjenige, der nach dem 8. April 1940 Handlungen ausgeführt hat, die ohne unter die Bestimmungen unter Nr. 1-3 zu fallen, von Bestimmungen des Strafgesetzes Kap. 8 oder 9 oder den Kriegsartikeln des Militärstrafgesetzes, vgl. Strafgesetz $\S 86$, betroffen sind, die Strafe für denjenigen festlegen, der während eines Krieges, an dem Norwegen beteiligt ist, dem Feind in Rat und Tat Beistand leistet.

Die Verordnungen in $\S 3$ bestimmen:

Verbrechen gegen § 2 werden mit Gefängnis oder Zwangsarbeit von bis zu 3 Jahren, Bußgeldern, Verlust des allgemeinen Vertrauens (Vertrauensverlust), vgl. § 11, oder begrenztem Rechtsverlust, vgl. § 12, oder mit mehreren dieser Strafen bestraft. Zudem kann als Zusatzstrafe, vgl. § 13, das Verbot festgesetzt werden, sich in bestimmten Gebieten aufzuhalten (Aufenthaltsverbot). 
Grundlage für den Bußgeldbescheid ist:

1. Der Beschuldigte hat im Teknisk Ukeblad vom 16. April 1942 einen propagandistischen Artikel über die Verhältnisse in Deutschland und die Wirkung der alliierten Bombenangriffe geschrieben.

2. Der Beschuldigte leistete am 3. Mai 1942 einen Beitrag in Höhe von 80 Kronen zur Freiwilligen-Legion Norwegen.

3. Der Beschuldigte arbeitete von Oktober 1943 bis April 1945 als Ingenieur in einer deutschen Elektrofabrik und erweiterte sein Patent auf Strahlentransformatoren. Als Vergütung für die Ausnutzung seines Patents erhielt der Beschuldigte 140.000 Kronen.

Die Strafe wird festgesetzt auf

I. Ein Bußgeld zur Staatskasse in Höhe von 5.000 Kronen

Bei der Festsetzung des Bußgeldes wurde berücksichtigt, dass der Beschuldigte 47 Tage Untersuchungshaft unterworfen war.

( 8 der Verordnung bestimmt ...)

(§ 9 der Verordnung bestimmt ...)

II. Verlust folgender Rechte:

1. Verlust des Stimmrechts bei öffentlichen Anliegen

2. Verlust des Rechts, Dienst in der Kriegsmacht des Reiches zu leisten Mit Rechtsgrundlage in $\S 15$ und $\S 16$ der Verordnung werden ihm weiter auferlegt:

Einzug von gesetzeswidrigem Verdienst in Höhe von 120.000 Kronen

( $\$ 15$ der Verordnung bestimmt ...)

( $\$ 16$ der Verordnung bestimmt ...)

Die Einzugsforderung stützt sich auf diese Gründe:

Der einzuziehende Betrag betrifft die Vergütung, die der Beschuldigte von den Deutschen dafür erhalten hat, sein Patent des Strahlentransformators für deutsche Interessen zur Verfügung gestellt zu haben.

(1. Absatz, § 25 der Verordnung bestimmt ...)

Der Beschuldigte wird aufgefordert, innerhalb von 5 Tagen nach Erhalt zu erklären, ob er den Bußgeldbescheid annimmt. Die Annahme kann erfolgen bei: Polizeibevollmächtigter Dreyer, Abteilung Landesverrat, Victoria Terrasse 5/7, Z.nr. 254, entweder mündlich oder schriftlich, indem ein Exemplar des Bußgeldbescheids unterzeichnet und zurückgesandt wird.

Wird der Bußgeldbescheid nicht angenommen, wird der Fall vor Gericht gebracht. In diesem Fall wird der Beschuldigte aufgefordert, in derselben, vorab benannten Frist anzugeben, welche Zeugen er angehört wünscht.

Das Dokument ist abgestempelt mit „Polizeibehörde Oslo“ und unterschrieben vom Polizeibevollmächtigten Gustav B. Dreyer. Am selben Tag, dem 2. November 1946, wird es von Rolf Widerøe unterzeichnet und die Unterschrift vom Polizeibevollmächtigten bestätigt. 


\section{Die durchgestrichenen Punkte}

Die drei unter "§ 2 der Verordnung" durchgestrichenen und somit nicht geltenden Punkte des Bußgeldbescheids sind folgende:

1. Derjenige, der nach dem 8. April 1940 Mitglied war, die Mitgliedschaft beantragt oder dieser eingewilligt hat von:

a) Nasjonal Samling oder der Partei verbundener Organisationen.

b) Einer anderen Organisation, die wider Bestimmungen der Kap. 8 und 9 des Strafgesetzes oder den Kriegsartikeln im Militärstrafgesetz agiert hat.

2. Derjenige, der nach dem 8. April 1949 solche, wie unter Nr. 1 benannte Organisationen oder von diesen begangene strafbare Handlungen unterstützt hat.

3. Derjenige, der nach dem 8. April 1940 gewerbsmäßige Tätigkeiten für den Feind ausgeführt oder sich daran beteiligt hat, in einer Weise oder unter Bedingungen, durch die das Verhältnis als ungebührlich angesehen werden muss. Als ungebührlich muss das Verhältnis im Allgemeinen angesehen werden u. a., wenn der Gewerbetreibende selbst die Verbindung mit dem Feind eingeleitet hat oder in engem Verständnis mit inm gearbeitet hat oder feindliche Hilfe ersucht hat, um Kontrolle oder gerichtliche Verfolgung zu verhindern oder zu erschweren, oder sich oder anderen einen ungebührlichen Preis oder Verdienst oder andere ungebührliche Vorteile verschafft hat.

Der für Rolf geltende Punkt 4 des Bußgeldbescheids fasst Handlungen zusammen, die nicht unter die drei durchgestrichenen Punkte fallen.

In dem endgültigen Bußgeldbescheid wird Rolf keine Strafe gemäß der provisorischen Anordnung vom 15. Dezember 1944 nach $₫ 2$, Absätze 1, 2 und 3, auferlegt, sondern nach $\$ 86$ des Strafgesetzes, der Strafe für denjenigen vorsieht, der während eines Krieges, an dem Norwegen beteiligt ist, dem Feind in Rat und Tat Beistand leistet.

\section{Fall abgeschlossen}

Mit Unterzeichnung des Bußgeldbescheids ist die rechtliche Verfügung abgeschlossen. Fertig. Fall beendet. Ein Bußgeld und die Aberkennung des Stimmrechts sowie des Rechts, norwegischer Soldat zu sein. Das ist die Strafe. Und das Verbrechen: ein Artikel im Teknisk Ukeblad, Geld für die Kriegsfreiwilligen, Patenteinnahmen in Deutschland. Rolf stimmte zu. Unterschrieb. Das war's.

So falsch kann man liegen.

Infolge der Akzeptanz des Bußgeldbescheids bekam Rolf seinen Pass zurück, wenn auch anfangs nur mit der Erlaubnis, nach Zürich zu reisen. 
Und das war auch das Erste, was er tat. Nach Zürich reisen. Für immer. Zu einem früheren Zeitpunkt im Herbst war er mit Frau und Kindern dorthin gefahren, und die Familie war bereits dort in einer Wohnung untergebracht. Er selbst war anschließend nach Oslo zurückgekehrt, um „die Vergangenheit" zu regeln. Jetzt eilte es jedoch, in die Schweiz zu kommen. Vergangenheit sollte Vergangenheit bleiben. Dachte er vermutlich.

\section{Überreaktion}

Professor Tor Brustad begnügte sich jedoch nicht damit, den Verlauf und den Bußgeldbescheid zu studieren. Er nahm sich alle Dokumente vor. Das endete in beißender Kritik speziell an bestimmten Aspekten der Arbeit des Sachverständigenkomitees, aber auch des Apparates drumherum und des Prozederes an sich. Die wesentliche Schlussfolgerung lautete: Es gab keine Grundlage für Rolfs Inhaftierung. Und: Die Zeit war längst reif, um ihm in der Geschichte den ihm gebührenden Platz als Begründer der BeschleunigerTechnologie einzuräumen. Mit anderen Worten: Rolf war von den groben Anschuldigungen des Landesverrats reingewaschen und sollte Brustads Meinung nach endlich seine Ehrung als Wissenschaftler erfahren. Die von ihm zusammengetragenen Fakten wie seine persönlichen Einschätzungen machte er im Mai 1997 auf einem internationalen Krebsseminar ${ }^{30}$ im norwegischen Hardanger und im Jahr darauf in einem Artikel in der wissenschaftlichen Zeitschrift Acta Oncologica öffentlich. ${ }^{31}$ Das akademische Milieu war nun informiert. Die Mehrheit der Bevölkerung wusste jedoch noch immer nicht, wer die Person Rolf Widerøe war, und hatte weder einen Bezug zur Anschuldigung wegen Landesverrat noch zur Reinwaschung. Und genau das war der Punkt von Professor Brustad, den er in Verbindung mit diesem Buch in mehreren Gesprächen betonte:

„Seine Arbeit in Deutschland während des Krieges und der anschließende Prozess gegen ihn durften viel zu lange überschatten, welch hervorragender Wissenschaftler und Technologe Rolf Widerøe war. Er verfügte über Eigenschaften, die ihm im Ausland die Ehrenbezeichnung 'Begründer der Beschleuniger-Technologie' einbrachten, während er bei uns nur zu einer Fußnote in der Physikgeschichte verkam. Es ist eine Krux, dass er in seinem Heimatland fast übersehen wird. Die wesentliche Ursache dafür liegt in gerichtlichen Verfügungen, die auf fehlerhaften Informationen darüber beruhen, woran er in Deutschland gearbeitet hat." 
Er kritisiert die Sachverständigen und sagt, dass sie „in der Peripherie, um nicht zu sagen, außerhalb ihres Mandats" sogar Zweifel an Rolfs Fähigkeiten als Erfinder und Wissenschaftler säten. Es missfiel ihnen, dass Rolf im Verhör darauf hingewiesen hatte, dass eines der Komiteemitglieder seine Arbeit zu einem früheren Zeitpunkt als ungeheuer wichtig bezeichnet hatte. In ihrem Bericht hatten sie die Aussage daher bagatellisiert und darauf verwiesen, dass das Lob nur für „einige wenige einfache Prinzipfragen über die Bewegung der Elektronen" gegolten habe.

Brustad ist in seinem Artikel nicht gnädig:

„Es muss eine ernsthafte Anklage gegen die Grundlage der gerichtlichen Verfolgung erhoben werden. Von der Verhaftung Widerøes im Mai 1945 bis zur Vorlage der Stellungnahme des Sachverständigenkomitees im Februar des darauffolgenden Jahres basierte der Fall auf einer äußerst ernsten Anzeige, die darauf hinauslief, dass Widerøe Steuerungsmechanismen für die gefürchteten deutschen V2-Raketen entwickelt habe. Daneben, dass die Anzeige von einer anonymen Quelle stammte und die einzige genannte Ursache für die Verhaftung war, zeigte sich, dass auch die falsch war, ohne Verankerung in der Wirklichkeit. Wäre der Fall gegen Widerøe auf eine Weise durchgeführt worden, die den Grundprinzipien unseres Rechtsstaats entspricht, wäre der anonymen Anzeige selbstverständlich nicht nachgegangen worden. Dann wäre Widerøe wahrscheinlich auch nicht verhaftet worden, zumindest hätte der ganze Fall dann eine andere und ausgeglichenere Wendung genommen."

An der Kritik hält er weiterhin fest und fügt hinzu:

„Als zudem bekannt wurde, dass Widerøe seine gesamte Zeit in Deutschland auf die Entwicklung eines operativen Betatrons verwendet hatte und dass die Arbeit keinerlei kriegswichtige Bedeutung für die Deutschen hatte, war klar, dass der ganze Prozess gegen ihn eine Überreaktion seitens der Behörden war."

Einen komplett konträren Standpunkt vertritt der ehemalige Industrieminister und langjährige Direktor des Forschungsinstituts der Armee, Finn Lied, als ihm der Fall gut 60 Jahre später vorgelegt wird. Sein Kommentar ist kurz und direkt:

„Wenn Rolf Widerøe für die Luftwaffe gearbeitet hat, ist er verdammt billig davongekommen. ${ }^{\text {"32 }}$

Lied gibt an, dass er Rolf als Physiker kannte und wusste, dass er während des Krieges in Deutschland gearbeitet hat, dass er jedoch nicht über die 
Details seiner Tätigkeit orientiert sei und auch nicht über das gerichtliche Nachspiel in Norwegen. Im Hinblick auf die Strafe ist Lied dennoch ganz deutlich und wiederholt mit Nachdruck, dass die Strafe - eine Geldbuße äußerst gering im Verhältnis zum Verbrechen war, wenn es unbestreitbar sei, dass Rolf von der Luftwaffe engagiert worden war.

Und es waren auch keine Lappalien, die das Sachverständigenkomitee da vorgebracht hatte, vor allem nicht in einer Anlage, die aus reiner Physik bestand. Darin zieht das Komitee in mehreren Punkten in Zweifel, ob das, was Rolf gemacht hat, wirklich etwas Neues und Haltbares darstellte oder ob das schlicht und einfach falsch war. Der Text ist von Skepsis durchzogen, sowohl die fachliche Kapazität generell betreffend als auch bezüglich der Arbeit, in Deutschland ein Betatron zu bauen. Beispielsweise heißt es:

„Da keines der Mitglieder des Komitees in der von Ingenieur Widerøe abgegebenen Darstellung all die komplizierten und unübersichtlichen Berechnungen der Linseneffekte hat kontrollieren können, hat eines der Mitglieder des Komitees eine gesonderte Berechnung vorgenommen. Diese zeigt, dass weder elektrische noch magnetische Linsen irgendeine spürbare Hilfe bei einem Betatron leisten würden, das bereits vorab vernünftig konstruiert ist. Im Gegensatz dazu hat Widerøe ..."

Und so setzt sich die fachliche Erklärung des Komitees fort. In den drei letzten und schlussfolgernden Abschnitten wird eine Kanonade deftiger Bewertungen abgefeuert:

„... vollkommen sinnlos ..."

„... gehört nirgendwo hin ..."

„... hat folglich die komplette Theorie missverstanden ..."

„... weder Widerøe noch seine Mitarbeiter scheinen Augenmerk darauf gelegt zu haben, dass ..."

„... Komplikationen, die in der Darstellung überhaupt nicht behandelt werden ..."

„... nicht einmal die Frage, wie Entladungen (...) vermieden werden können, ist erwähnt ..."

Um die Kritik gleichsam zu besiegeln, lautet ein letzter tödlicher Satz:

„Die Idee elektrostatischer Linsen erscheint daher so wenig durchdacht, dass sie keineswegs ernst genommen werden kann, ganz abgesehen von den Rechenfehlern. “"33 


\section{Nicht alles ist Rechtswissenschaft}

Nach einer solchen Salve an Desavouierung und Missbilligung durch Fachkollegen wird man neugierig. Was meinten sie damit? Verstanden sie nicht oder wollten sie nicht verstehen?Traf Letzeres zu?

Vor Ernennung des Sachverständigenkomitees, während Rolf noch im Gefängnis saß, waren die Amerikaner involviert gewesen. Ein Offizier des Nachrichtendienstes hatte ihn im Gefängnis aufgesucht. Am Nachmittag desselben Tages wurde er entlassen. Der Mann war identisch mit einem der späteren Mitglieder des Sachverständigenkomitees. Damit stehen wir vor einem anderen Mysterium.

Der Besucher war Gunnar Randers, der seit Herbst 1944 für den amerikanischen Militärgeheimdienst gearbeitet und Verbindung zur Operation Alsos hatte, wohinter sich ein Teil des Manhattan-Projekts verbarg, das untersuchte, wie weit Hitler-Deutschland mit der Atombombe gekommen war. Seine Basis war Paris, jedoch reiste er die meiste Zeit durch Europa. An einem Junitag im Sommer 1945 befand sich Randers also im Ilebu-Gefängnis für Landesverrat. Dort sollte er herausfinden, was Rolf wusste. Am selben Tag gab es eine totale Sonnenfinsternis, und ein solches Phänomen ließ sich der Astrophysiker nicht entgehen. Er hatte eine verrußte Glasscherbe dabei, durch die sie beide die Sonne betrachten konnten. Vielleicht trug das auch dazu bei, die Stimmung aufzulockern, Rolf deutete das zumindest als gutes Zeichen. Die Sonnenfinsternis sollte gegen ein Uhr beginnen, und die beiden Physiker sahen sie sich nicht nur an, sondern sprachen auch über Physik. Jedoch ahnten beide nicht, dass sie noch mehr miteinander zu tun haben sollten ... und das nicht nur einmal.

Abgesehen davon, dass Rolf angegeben hat, er habe von der Arbeit am Betatron erzählt, sind keine Details von der Begegnung bekannt, weder von der Absicht dahinter noch vom Ergebnis. Auch waren öffentlich keine Fragen zum Zusammenhang zwischen dieser Begegnung und Rolfs Entlassung gestellt worden. Einige dachten vielleicht, dass es ganz einfach eine kollegiale Geste war, einen inhaftierten Physiker zu besuchen, und dass Rolf noch am selben Nachmittag entlassen wurde, wurde als ein Zufall betrachtet, falls es überhaupt bekannt war. Und sollte man gestutzt haben, dachte man vermutlich, der Besucher müsse gute Kontakte gehabt und bei den Gefängnisbehörden oder der Polizei vielleicht ein gutes Wort eingelegt haben. Und weiter nichts.

Was nur Eingeweihte wussten, war, dass das Gespräch im Gefängnis wortgetreu niedergeschrieben und in die USA geschickt wurde. Im Archiv 
des American Institute of Physics in Maryland befindet sich heute eine dicke Mappe mit der Aufschrift „Rolf Widerøe Papers, 1942-1945“. Darin liegt ein Ordner, auf den Gunnar Randers per Hand geschrieben hat: „Visit to Widerøe in Oslo. July 1945, Capt. G. Randers".

Professor Brustad hat das Dokument zur Kenntnis genommen, als er das Material im Zentralarchiv durchging, und es in seinen Artikel aufgenommen:

„Die Alliierten hatten über einen langen Zeitraum hinweg umfassende Untersuchungen der kompletten deutschen militärischen Forschungstätigkeit durchgeführt. Norwegen war daran beteiligt und durch Gunnar Randers vertreten, der zu dieser Zeit den Titel Hauptmann hatte." ${ }^{\text {"34 }}$

Brustad konstatierte, dass Norwegen dadurch „vollen Überblick über Widerøes Arbeit in Deutschland erhalten hatte". Aber möglicherweise war die Information über Ermittlungen im Forschungsmilieu für einen erfahrenen Professor nicht so aufsehenerregend, denn er vertiefte es nicht. Niemand schien sich für die zeitliche Nähe von Randers' Besuch und Rolfs Entlassung zu interessieren. Damals nicht und später nicht. Auch Rolf schmückte das nicht aus, obwohl er der Meinung war, er sei dank Randers und seines Freundes und Kollegen Odd Dahl entlassen worden, und nahm an, den beiden sei es gelungen, die Behörden davon zu überzeugen, dass er im Gefängnis nichts zu suchen habe, während er auf die Behandlung des Falls wartete. In der Biografie sagt Rolf über Gunnar Randers nur: „Er hatte den Auftrag, mit mir zu reden, wahrscheinlich wegen der V2-

Gerüchte.“

Das Seltsame ist, dass niemand dem nachgegangen ist, was Rolf hier äußert, nämlich, dass die Alliierten von seiner Beschäftigung bei der deutschen Waffenindustrie wussten und es verständlich war, dass er aufgesucht wurde. Und wenn es sich so verhielt, dass die Alliierten orientiert waren - welche Konsequenzen hatte das? In welche Richtung wies das im Hinblick auf die Schuldfrage? Verschärfte oder milderte das die Umstände? Darauf ist niemand eingegangen. Noch mehr muss man sich jedoch wundern, warum er selbst es nicht weiterverfolgt hat.

Wusste er es nicht besser? Erneut bleibe ich mit einer dieser Fragen zurück, von denen es rund um Rolf so viele gibt. Erneut lese ich die Biografie und prüfe Aussagen, die er an anderen Stellen zu dem Thema gemacht hat, unter anderem in einem Videointerview, das Pedro Waloschek im Zusammenhang mit seinem Buch mit Rolf führte. Dann höre ich mir erneut die Aufnahme vom Physiker-Interview in Oslo an. ${ }^{35}$ Ich grüble 
darüber nach, was Rolf in den Interviews gesagt hat und was er den Autor der Biografie hat schreiben lassen. Ich lese seine Korrekturen und Durchstreichungen in den von ihm durchgesehenen Fassungen. Was stehen blieb, ist Inhalt, für den er garantierte. Im Buch, im Video und auf Tonband nahezu Wort für Wort identisch. Wie eine auswendig gelernte Hausaufgabe. Ich wiederhole die Sätze, und in meinem Kopf spielt sich ein fiktiver und leicht tadelnder Dialog ab, während Rolf von Gunnar Randers' Besuch bei ihm im Gefängnis erzählt:

„Er kam direkt aus Amerika, mit dem Auftrag herauszufinden, was los war. Ich erklärte ihm alles genau, und er verstand sofort, dass ich nichts mit Peenemünde zu tun hatte. Und offensichtlich hat er sich dann dafür eingesetzt, dass ich freigelassen werde."

"Es war also so einfach, dass Sie einfach entlassen wurden, nachdem er dort gewesen war? Wie war das möglich?"

„Ich bekam die Gelegenheit, die Umstände rund um meine Arbeit in Deutschland zu erklären, und - nicht zuletzt - wirkte es auf mich, als kämen wir gut miteinander aus."

"Sie wurden am selben Tag entlassen, erwähnen das jedoch nicht. Warum sind Sie in diesem Punkt nicht deutlich? Das müsste für eine Biografie wichtig sein? War Physik wichtiger?"

„Er war eine Zeit lang in Amerika gewesen und dann nach Norwegen zurückgekehrt, um sich in der Astrophysik und in der Kernphysik zu engagieren."

„Darüber erzählen Sie! Aber sehen Sie nicht, dass Sie die Verbindung zum amerikanischen Geheimdienst verschleiern, indem Sie die Aufmerksamkeit auf die Physik und die neue Karriere in der Heimat lenken? Hatten Sie versprochen, darüber zu schweigen? War das etwas, das die Sowjetunion nicht erfahren sollte? Und dann die große Frage, zu der ich immer wieder zurückkehre: Warum haben Sie das der Staatsanwaltschaft gegenüber nicht erwähnt? Warum haben Sie nicht gesagt: 'Hören Sie, es gibt mildernde Umstände.' Oder gab es die nicht? Oder taten Sie es? Ein intelligenter Mann wie Sie muss begreifen, dass aus so etwas Verschwörungstheorien erschaffen werden."

Das jedoch habe ich ihm nie gesagt. Und ich bekam keine Möglichkeit, eine Zurückweisung zu erhalten. Allerdings hatte er in Tor Brustad auch einen guten Sprecher. 


\section{Tendenziös}

Der Professor vom Radiumhospital macht kein Hehl daraus, dass er vielem von der Arbeit der Sachverständigen kritisch gegenübersteht. Er hat durchaus ein Hühnchen mit dem kompletten Komitee zu rupfen und ist der Meinung, es sei mitschuldig daran, dass Rolf das wurde, was er als eine „Fußnote in der norwegischen Physikgeschichte“ bezeichnet. ${ }^{36}$ Besonders stellt er sich gegen die Haltung, die seiner Ansicht nach die Stellungnahme des Komitees durchzog:

„Leider war das Komitee von dem Geist und der Haltung beeinflusst, die 1945/46 so vordergründig bestand, und war enorm negativ gegenüber allem, was mit der Zusammenarbeit mit den Deutschen zu tun hatte."

In einem wichtigen Punkt erweist er dem Komitee jedoch seine Anerkennung, nämlich dafür, dass es zur Aufklärung darüber beigetragen hat, dass Rolf nichts mit der Entwicklung der deutschen V-Bomben zu tun hatte. Daher lohnt es sich, diesen Punkt näher zu beleuchten. In seinem Artikel hat Brustad das wie folgt zusammengefasst und kommentiert:

„Obwohl die wesentliche Schlussfolgerung der Stellungnahme in selbiger auf verschiedene Stellen verteilt ist, mitunter eingezwängt in langen und schwierigen Formulierungen, kann sie in drei Sätzen zusammengefasst werden:

1. Widerøe hatte nichts mit den V2-Raketen zu tun.

2. Widerøe hat seine gesamte Zeit während des Deutschland-Aufenthalts auf die Arbeit mit der Entwicklung eines operativen 15-MeV-Betatrons verwendet.

3. Widerøes Arbeit in Deutschland hatte für die Deutschen keinerlei militärische Bedeutung. “37

Obwohl diese Schlussfolgerungen Brustad zufolge unvermeidlich waren, verdienen die Sachverständigen Lob für diesen Teil ihrer Arbeit, bedenkt man die zu dieser Zeit in Norwegen herrschende verbissene antideutsche Haltung. Heute wissen wir, dass Punkt 2 faktisch nicht ganz korrekt ist. Hier war das Komitee zu „nett“, wissentlich oder unwissentlich, und dasselbe trifft auf Brustad zu. Denn in Wirklichkeit machte Rolf auch andere Dinge. Das heißt, auf eine Weise hat das Komitee recht, denn die einzige Maschine, die physisch gebaut wurde, war das 15-meV-Betatron. 
Gleichzeitig aber arbeitete Rolf an Ideen für andere und größere Maschinen. Wie detailliert die Komiteemitglieder darüber informiert waren, ist schwer zu sagen.

\section{Mangelhaft}

Brustad stellt auch die Frage, warum die Sachverständigen nichts von dem anführten, was Rolf gelungen war, wohingegen sie scheinbar großes Interesse an dem Misslungenen hatten. Warum wurde nichts über den Erfolg bei der Konstruktion des weltweit ersten Linearbeschleunigers gesagt? Über das Patent für das Prinzip der sogenannten kollidierenden Strahlen? Über das Patent für die grundlegenden Prinzipien des Synchrotrons, die er faktisch während seiner Zeit im Gefängnis Ilebu entwickelte? Diese rhetorischen Fragen stellt Brustad, demzufolge das Komitee auch kein Gewicht darauf legte, dass Widerøe Patente angemeldet hatte und norwegischen Behörden die Zusammenarbeit anbot, indem er ihnen Zugang zu dem Material und dem Wissen gab, das er sich in Deutschland angeeignet hatte.

Tor Brustad meint, obwohl das Sachverständigenkomitee über eingehendes Wissen zu Rolfs Arbeit in Deutschland verfügte, habe es nur eine vage Erklärung dafür abgegeben, warum die Deutschen den Wunsch hatten, Widerøe für das Betatron-Projekt zu engagieren. ${ }^{38}$ Er verweist darauf, dass in dem Bericht nur zwei Begründungen genannt werden. Die eine war, dass in einem Betatron produzierte hochenergetische Strahlen eingesetzt werden konnten, um Flugzeuge des Feindes außer Gefecht zu setzen. Darüber schreibt Brustad:

\footnotetext{
„Das Komitee machte gegenüber der Staatsanwaltschaft (die selbstverständlich keine Kenntnisse über diese Technologie hatte) nicht deutlich, dass diese Pläne total unrealistisch waren: Denn wie könnte ein Strahl in der Dicke eines Kugelschreibers vom Koloss eines 1944er-Betatrons gegen eines der Flugzeuge des Feindes gerichtet werden, das sich hoch oben und schnell bewegt, und mit seiner - für ein solches Ziel lächerlichen - Strahlenintensität eine Strahlendosis aussenden, die ausreicht, um den Piloten zu töten und/oder das Radarsystem außer Gefecht zu setzen? “39
}

Der andere vom Komitee herangezogene Grund ist laut Brustad der, dass die Deutschen eventuell „den Wunsch [hatten], mit den Amerikanern auf dem neuen Gebiet zu wetteifern, welches möglicherweise Bedeutung für die Atomphysik erlangen könnte, und indirekt auch für eine Atom- 
waffe “. ${ }^{40}$ Eine vollständige Deutung dessen, was diese beiden Argumente beinhalteten, wurde der Staatsanwaltschaft überlassen. Das Komitee konstatierte nur:

„Es ist klar, dass Schiebolds fantastische Ideen von 'Todesstrahlen' (zur Anwendung gegen Flugzeuge) eine mitwirkende Ursache dafür waren, dass die Deutschen sich Widerøe sicherten. Daneben hat der Wunsch, mit den Amerikanern auf einem neuen Gebiet zu wetteifern, das vielleicht Bedeutung für die Atomphysik haben könnte und dadurch auf Umwegen möglicherweise auch für Atomwaffen, eine gewisse Rolle gespielt. “41

Aus Brustads Sicht war die Stellungnahme des Komitees also nicht nur tendenziös, sondern auch mangelhaft.

\section{Unlogisch}

Aber er geht noch weiter und verweist auf logische Brüche im Räsonnement des Komitees. Er meint, es wurde angedeutet - ohne irgendeine Form der Beweisführung -, dass die deutsche Delegation auf eine mögliche militärische Ausnutzung des Projekts aus war. Und es wurde unterstellt, dass Rolf womöglich zugestimmt habe, sich an so etwas zu beteiligen. Das wurde Brustad zufolge von Rolf heftig zurückgewiesen. In der Tat wäre es von der Delegation vollkommen unlogisch gewesen, durch Gerede über mögliche militärische Aspekte die eigenen Pläne zu ruinieren. Rolf hätte das ganze Waffenprojekt als Unsinn entlarvt, was sein Vertrauen zu dem Projekt und den Unterhändlern geschwächt hätte. Außerdem hätten militärische Aspekte völlig unnötig Rolfs Nationalgefühl provoziert, was die Deutschen gerade vermeiden wollten.

Tor Brustad ist der Meinung, dass sowohl die Staatsanwaltschaft als auch das Expertenkomitee Rolfs Beteiligung am Hamburg-Projekt als Beweis für fehlende nationale Loyalität angesehen haben. Es scheint, als sei die einzige Entschuldigung, die sie für die Zusage zu einem solchen Projekt hätten akzeptieren können, vorzulegende Beweise darüber, dass er Bedrohung und Gewalt ausgesetzt worden sei, so Brustad, der seine Aussage wie folgt vertieft:

„Rolf war für den deutschen Sicherheitsdienst so wichtig, dass dieser nie zugelassen hätte, dass er den Alliierten in die Hände fällt. Sie wussten außerdem, dass es ihnen gelingen würde, ihn 'unter Kontrolle' und mit seinem 
Betatron-Projekt beschäftigt zu halten, weil sie die Trumpfkarte hatten - eine verschleierte Drohung, die Erfolg garantierte, ohne Zuflucht in Gewalt zu suchen. Hätte er die Zusammenarbeit an dem Projekt abgelehnt - um nicht von der Zusammenarbeit mit den Alliierten zu sprechen - oder wäre er nach einem Besuch bei der Familie in Oslo nicht zurückgekehrt, ist ziemlich sicher, dass der Sicherheitsdienst ihn unmittelbar dazu gebracht hätte, die Sache zu überdenken. Sie hätten lediglich beim Bruder die Daumenschrauben anziehen müssen. Deshalb dachte der Sicherheitsdienst zu keiner Zeit daran, Viggo aus dem Gefängnis zu entlassen. Indem sie Viggo als 'Geisel' festhielten, hatten sie Kontrolle über seinen für sie viel wichtigeren Bruder. Auf diese Weise wurden beide zur Geisel des jeweils anderen."

Professor Brustad zufolge gibt es keinen Zweifel, dass das Sachverständigenkomitee wusste, dass das Todesstrahlen-Projekt der Deutschen technologisch vollkommen hoffnungslos war. Damit bleibe als Begründung für den Wunsch der Deutschen, dass Rolf für sie arbeitet, nur das windige Argument des Konkurrenzaspekts übrig.

„Das Komitee schlussfolgerte jedoch, dass er all seine Zeit auf die Entwicklung des $15-\mathrm{MeV}$-Betatrons verwendet habe, und dass diese Arbeit für die Deutschen von keinerlei militärischer Bedeutung war. Wenn die Motivation der Deutschen wirklich darin bestand, Widerøe für die Realisierung eines Projekts ohne jegliche militärische Bedeutung zu engagieren, dann ist das schwer zu verstehen, auf einer Ebene mit Fragen wie: Warum wurde Widerøe als Leiter des Projekts eingesetzt, und das mit der Befugnis, es so durchzuführen, wie er es wollte?“

Dass er die Leitung innehatte, habe er selbst bestätigt, so Brustad mit Verweis auf die Informationen, die Rolf für die Polizeibehörde Oslo zusammengestellt hatte, um spezifische Fragen des Sachverständigenkomitees zu beantworten. In Dokument 15 Punkt 6 fragt das Komitee: „Welche Forderungen stellten die Deutschen im Hinblick auf die Ergebnisse der Arbeit?“" Widerøe antwortet: „Keine speziellen Forderungen, abgesehen davon, dass die Entwicklung so schnell wie möglich vonstattengehen solle. Mir oblag die technische und die wissenschaftliche Leitung. “42

Generell, findet Brustad, gibt es viel, auf das die Stellungnahme keine Antwort gibt: Warum wurde Rolf ohne offenbaren Einsatz von Gewalt nach Deutschland geschickt? ${ }^{43}$ Warum wurde er so generös mit finanziellen, personellen und industriellen Ressourcen versorgt? Warum wurden ihm während seines Aufenthalts in Deutschland so viele Freiheiten und so gute 
Möglichkeiten gewährt, zwischen Oslo und Hamburg hin und her zu reisen? Ja, warum leitete er die Zusammenarbeit überhaupt ein?

\section{Was ist geschehen?}

Der Expertenbericht stellte in dem ganzen Prozess eine dramatische Einlage dar; das erkennt man durch den Einblick im Nachhinein. Der Ausgang muss jedoch von mehreren Faktoren beeinflusst worden sein.

Zwischen Rolfs Inhaftierung im Mai und dem Bußgeldbescheid im November anderthalb Jahre später ist etwas passiert. Ein Mann wird dafür verhaftet, an der Herstellung einer der gefährlichsten Bomben der Welt beteiligt gewesen zu sein, und das Ganze endet mit einem Bußgeld, als handle es sich um ein Verkehrsdelikt. Es heißt zwar vereinfachter Bußgeldbescheid und es steht eine erheblich größere Summe als bei einem solchen Vergehen im Raum, juristisch ist jedoch trotzdem von einer so milden Übertretung die Rede, dass man lediglich ein Bußgeld auferlegt bekommt. Akzeptiert und bezahlt man, ist die Sache seitens der Staatsanwaltschaft aus der Welt.

Die Anschuldigung gegen Rolf, die zwar im Verhältnis zur Anzeige stark gemäßigt war, blieb weiterhin sehr ernst. Letztendlich ergab sich daraus aber dennoch kein Prozess. Keiner der Akteure stellte in Vertretung der Staatsanwaltschaft die Forderung nach Verhaftung. Keine Geschworenen, kein Richter, keine sogenannte Hauptverhandlung, keine Urteilsverkündung vor Gericht. Nach einem Jahr und sechs Monaten wird alles auf die einfachste Weise beendet - mit einem Bußgeldbescheid. So wie es in vielen Fällen geschah. Der Bußgeldbescheid entsprach gleich nach dem Krieg einer allgemeinen Form der Reaktion. In den offiziellen Angaben des Statistischen Zentralbüros zum Thema Landesverrat in den Jahren 1940-1945 wird etwas über das Warum gesagt:

„Der Bußgeldbescheid kann im Allgemeinen bei geringeren Strafsachen angewendet werden, wo die Strafe nur auf ein Bußgeld hinausläuft, ev. in Verbindung mit Einzug (siehe Strafprozessrecht vom 1. Juli 1887, $\$ 287$ ). Ein beschlossener Bußgeldbescheid hat dieselbe Wirkung wie ein Urteil. In Fällen von Landesverrat war die Möglichkeit, einen Fall durch Bußgeldbescheid zu entscheiden, stark erweitert gewesen. Im Brief des Obersten Staatsanwalts an das Justizministerium vom 25. November 1947 über die Begrenzung der gerichtlichen Verfolgung von Landesverrat steht u. a.: Ein bedeutungsvolles Mittel, die gerichtliche Verfolgung durch Vereinfachung des Prozederes zu 
beschleunigen, war die Regelung, die durch Gesetz Nr. 2 vom 22. Februar 1946 eingeführt wurde, über die Möglichkeit der Staatsanwaltschaft, Bußgeldbescheide mit Freiheitsstrafen von bis zu 1 Jahr auszustellen. “44

Rolf gehörte also zu der Kategorie Menschen, die Bußgeldbescheid und Bußgeld erhielten. Er hatte anderthalb Monate im Gefängnis gesessen, wobei es sich aber um Untersuchungshaft handelte, die für gewöhnlich angeordnet wird, damit - in Erwartung der Anklage - keine Beweise verloren gehen. Der Ausgang des Falls zeigte, dass es keine Grundlage für eine Gefängnisstrafe gab. Stattdessen wurde es ein Bußgeld. Das sollte doch in Ordnung und hinreichend klärend sein. Aber das Ganze hatte so heftig angefangen. Ist sicher, dass wir jetzt alles wissen? Oder wussten die Behörden etwas, das wir nicht erfahren haben? Rolf war faktisch nachweisbar im Auftrag der Luftwaffe des Feindes tätig gewesen. Hatte sogar daran verdient.

Zwischen dem Vorliegen der Stellungnahme des Komitees und dem Ergebnis der Staatsanwaltschaft verging viel Zeit. Darüber, ob das der Vielzahl an Fällen geschuldet war, die vor Gericht gebracht werden sollten, oder ob Rolfs Fall besonders schwierig war, ist in der Dokumentation nichts zu finden. Ersteres war zumindest der Fall. Über 90.000 Personen wurden des Landesverrats beschuldigt, etwa 30.000 verhaftet. Es brauchte unausweichlich Zeit, alle diese Fälle zu bearbeiten. Die Hälfte derer, die nach dem Landesverrat-Paragrafen, $\$ 86$ des Grundgesetzes, beschuldigt wurden, erhielt ein Strafe, die Hälfte davon ein Bußgeld. Mit anderen Worten: Über ein Viertel der Fälle endete mit einem Bußgeld. ${ }^{45}$

\section{Die Pass-Frage}

Während der Fall insgesamt in relativer Ruhe ablief, wurde - vor allen Dingen - die Frage nach der Aushändigung von Rolfs Pass zu einer großen Sache. Ihm lag das Angebot für eine Stelle am Hauptsitz von Brown Boveri in der Schweiz vor, wo er die technische Entwicklung von Betatronen auf industrieller Basis leiten sollte. Auf Wunsch der Firma sollte er so schnell wie möglich mit der Konstruktion einer Maschine für das Krankenhaus in Zürich beginnen, zudem wünschte das Unternehmen selbstverständlich ein Treffen mit ihm. Der begehrte Norweger war aber nicht nur inhaftiert worden, sondern man hatte ihm auch den Pass und jedwede Ausreisemöglichkeit entzogen, auch nach seiner Entlassung.

Am 1. März 1946 schickte Rolf einen Brief an den Sachbearbeiter der Staatsanwaltschaft, Gustav B. Dreyer, und beantragte, so schnell wie mög- 
lich in die Schweiz reisen zu dürfen, um die Geschäftsleitung von Brown Boveri zu treffen. Er begründete das mit zwei Dingen: Zum einen konnte er nicht mit dem vom Radiumhospital bestellten Betatron beginnen, bevor er nicht mit dem Labor in der Schweiz wichtige Fragen betreffs der Konstruktion geklärt hatte. Zum anderen musste er mit ihnen über ein Patent sprechen, für das sich besonders in den USA großes Interesse regte. ${ }^{46}$

Wie sich zeigte, sollte die Frage bezüglich der Aushändigung des für weitaus mehr Aufmerksamkeit sorgen als die Tatsache, dass man ihn wegen Landesverrat inhaftiert hatte. Und ohne Pass kam er zu keiner Besprechung bei Brown Boveri. Den Pass zurückzubekommen war jedoch schwer, solange der Fall gegen ihn noch nicht abgeschlossen war. Tor Brustad verweist auf die Ironie in dem Ganzen: Während man Rolf in der Schweiz auf Grundlage der Kompetenz, die er sich erarbeitet hatte, eine attraktive Stelle in der Forschung und Entwicklung anbot, war er in Norwegen wegen derselben Arbeit und derselben Kompetenz als Landesverräter verhaftet worden.

\section{Das Radiumhospital meldet sich zu Wort}

$\mathrm{Zu}$ dieser Zeit hatte man im Radiumhospital in Oslo begonnen, Pläne zur Anschaffung neuer Ausrüstung für die Strahlenbehandlung zu machen. Beschleunigergenerierte Strahlung mit hoher Energie galt auf dem Gebiet der Krebsbehandlung als das Allerneueste und der Direktor war sich im Klaren darüber, dass die einzukaufende Ausrüstung so fortschrittlich sein musste, dass sie das Radiumhospital an der Front der Revolution platzierte, vor der die Strahlentherapie aktuell stand. Die Frage lautete, wo die beste Ausrüstung zu bekommen war.

Zusammen mit dem Direktor von NEBB schrieb er einen Brief an die Staatsanwaltschaft, worin beide baten, dass Rolf die Möglichkeit erhielt, in die Schweiz zu reisen, um in Verbindung mit der Entwicklung neuer Technologien für die Strahlentherapie an einem vorbereitenden Treffen teilzunehmen. Ihnen zufolge sei diese Arbeit von großer gesellschaftlicher Bedeutung, weil viele Krebspatienten auf diese Weise eine bessere Behandlung erhielten. ${ }^{47}$

\section{Der Sachbearbeiter meldet sich zu Wort}

Als Rolf von der Initiative der beiden erfuhr, reichte er im Herbst und Winter wiederholt Anträge ein, um seinen Pass zurückzubekommen, 
berichtet Brustad und äußert sich hinsichtlich des weiteren Geschehens erstaunt:

„Der Sachbearbeiter bediente sich eines überraschenden Kniffs. Er band das Sachverständigenkomitee ein. Jene vier, die ernannt worden waren, um der Staatsanwaltschaft in physikfachlichen Fragen beizustehen, sollten sich jetzt zu der Frage 'Pass oder kein Pass' äußern. Das sorgte für zusätzliche Dramatik. Das Komitee widersprach sämtlichen Anträgen resolut, widersetzte sich konsequent jeglicher Aushändigung des Passes."

In dem Artikel zitiert Brustad einen der Antwortbriefe des Komitees, um „die Haltung des Komitees zu illustrieren, sowohl was die Passausstellung als auch die Person Widerøe betraf":

\begin{abstract}
„Wie aus der Erklärung des Komitees hervorgehen wird, wird Ing. Widerøes geplante Reise nach Baden (Schweiz) nicht als gesellschaftlich bedeutend betrachtet, sondern dient lediglich seinem persönlichen Interesse. Die Frage bezüglich des Passes ist eine Angelegenheit der Polizei, für die das Sachverständigenkomitee keine Verantwortung tragen will. Es will indessen anmerken, dass Widerøe durch eine solche Reise ungehindert die Möglichkeit erhält, seinen ausländischen Verbindungen seine Auffassung dieser Angelegenheit darzulegen - auch im Hinblick auf hypothetische norwegische Interessen. Das Zustandekommen der Einladung von Brown Boveri muss zweifellos der Eigeninitiative von Widerøe zugeschrieben werden. “ ${ }^{4}$
\end{abstract}

Das Komitee gibt also an, nichts mit der Frage zu tun haben zu wollen, weil die Klärung dessen in der Verantwortung der Polizei läge. Dennoch äußert es seine Meinung zu der Sache und unterstellt, Rolf habe das Ganze selbst organisiert, so Brustad, der anschließend von einer neuen Wende in der Passfrage berichtet:

„Da greift nämlich der Sachbearbeiter der Polizeibehörde Oslo ein. Erneut. Denn als bekannt wurde, dass die Anklage hinsichtlich einer Mitarbeit an den deutschen V-Bomben Erfindung war, fand er, die ganze Sache gegen Rolf Widerøe habe einen so untergeordneten Charakter, dass er auf eigene Faust gestatten könne, dass er einen Pass erhielt, um so an dem Treffen mit Brown Boveri teilnehmen zu können."

Es ist leicht, sich die Schmach und den Prestigeverlust gegenüber dem Umfeld vorzustellen, wenn er die Ausreiserlaubnis nicht erhalten hätte. Die eigenen Finanzen, die zukünftige Arbeitsstelle sowie Ruhm und Ehre 
standen auf dem Spiel. Daher gibt es keinen Zweifel daran, dass er viel investiert hat, um reisen zu können. Hier aber drehte es sich um Formalitäten. Und vielleicht um ein bisschen mehr als das. Die Sache ist, dass er nicht aufgibt und zum Schluss tatsächlich Erfolg hat. Nach diversen Ablehnungen, wiederholten Anträgen und Druck von verschiedenen Seiten gelingt es, dass man ihm im Frühjahr 1946 einen vorübergehenden Pass ausstellt. Nach Ostern reist er dann für einige Wochen zu Besuch an Brown Boveris Hauptsitz.

Seine Aufmerksamkeit dreht sich nun mehr und mehr darum, mit dem Betatron voranzukommen, das er für die Schweizer bauen soll. Deshalb wird er langsam ungeduldig, was den Fortgang im Fall der Anschuldigung auf Landesverrat betrifft. Am 7. Juni 1946 sendet er einen Brief an die Polizeibehörde Oslo und Aker, in dem er darum bittet, dass sein Fall „baldmöglichst entschieden wird". Er berichtet von Besprechungen mit dem Oberarzt des Krankenhauses in Zürich, dessen Aussagen „äußerst alarmierend“ seien. Sie gingen davon aus, „dass es im Laufe der nächsten Jahre an europäischen Krankenhäusern einen katastrophalen Mangel an Röntgenröhren zur Krebsbehandlung geben würde“. Der Grund war, dass Siemens nicht mehr ausreichend Röntgenröhren liefern konnte. Vor und während des Krieges hatte das Unternehmen sozusagen den kompletten Markt abgedeckt, aufgrund der Verhältnisse in Deutschland konnte es derzeit aber nur etwa fünf Prozent seiner normalen Produktion liefern. Dieses Problem könne sein Strahlentransformator lösen, weil der Apparat „mindestens 5-10 übliche Röntgenröhren ersetzen“ könne, und daher sei es „von allergrößter Bedeutung, so schnell wie möglich krankenhausfertige Apparate liefern zu können", schreibt er.

Er verweist auch auf den Direktor des Radiumhospitals, nach dessen Ansicht man dort so schnell wie möglich moderne Behandlungsapparate installieren müsse. Das sei jedoch „eine Sache, deren Bedeutung nicht auf Norwegen begrenzt ist". Vielmehr treffe das auf viele andere Länder Europas zu, und dann greift er zu großen Worten:

„Ich bitte Sie daher, die großen humanitären Interessen zu berücksichtigen, die hier auf dem Spiel stehen, und nach Möglichkeit dazu beizutragen, dass unsere Arbeit nicht verzögert wird. Ich bitte darum, dass mein Fall baldmöglichst behandelt wird, damit ich im August dieses Jahres die Arbeit in Baden aufnehmen kann.“

Unterzeichnet: „Hochachtungsvoll Rolf Widerøe“ 49

Kein Wort über den Fall an sich oder dessen Ausgang. 
Vier Wochen später schreibt er erneut einen Brief, dieses Mal direkt an den Kriminalchef der Abteilung Landesverrat, Lars L'Abée Lund, adressiert. Er legt einen Ausschnitt aus der Neuen Züricher Zeitung über Brown Boveris Engagement hinsichtlich seines Strahlentransformators bei und schreibt, dass es „sehr dringend“ sei, dass er mit der Arbeit beginne:

„Die Konstruktion des Apparates hat jetzt den Punkt erreicht, an dem meine persönliche Anwesenheit notwendig ist, und man bittet mich daher, so bald als möglich in die Schweiz zu kommen. Diesbezüglich bitte ich Sie eindringlich, meinen Fall bestmöglich zu beschleunigen, damit ich meine Reise wie geplant am 17. August, mit Ankunft in Baden am 21. August, antreten kann. Hochachtungsvoll Rolf Widerøe" 50

Auch hier kein Versuch zu argumentieren oder sich reinzuwaschen. Lediglich die Bitte um Beschleunigung des Verfahrens, damit er vorankommt.

Und er kommt im August nach Zürich. Von dort aus schreibt er seinem Verteidiger und fragt, ob es wirklich notwendig sei, dass er nach Norwegen zurückkehre, um später im Herbst zum Abschluss des Falls anwesend zu sein. Denn würde es sich nur um Formalitäten handeln, sollte das durch den Anwalt und per Brief geregelt werden können. Dann greift er die Frage bezüglich eines permanenten Passes auf. Der Rest des Briefes handelt von dem Apparat, den er entwickelt, der für $1100 \mathrm{meV}$ geplant ist und eventuell auf Rechnung des Schweizer Staates gebaut werden soll. ${ }^{51}$ Das beschäftigt sein Denken. Sein Umfeld sieht das jedoch anders.

\section{Die Medien melden sich zu Wort}

Jetzt fehlten nur noch die Medien, damit die Pass-Angelegenheit wirklich große Kreise zog. Und selbstverständlich kam es dazu, nicht unerwartet ausgelöst durch die Schweiz-Reise. Denn als bekannt wurde, dass eine Person, die gemäß Landesverratsverordnung beschuldigt war, außer Landes hatte reisen dürfen, ging das Gezeter los. Das stieß den Mitgliedern des Sachverständigenkomitees bitter auf, obwohl sie den Passantrag nicht bewilligt hatten. Doch das Problem war, dass jemand genau das glauben könnte, und es galt sich reinzuwaschen, bevor jemand auf diesen Gedanken kam. Kein guter Norweger konnte es auf sich sitzen lassen, gegen Landesverräter nicht hart durchzugreifen. Als im Laufe des Sommers bekannt wurde, dass Rolf einen Pass bekommen hatte, startete nicht zuletzt im Dagbladet eine gehässige Initiative gegen jene, die nach Meinung der Zeitung für die 
Ausstellung des Passes verantwortlich gewesen waren, sagt Brustad. Der Kriminalchef hatte die Presse gewiss darüber informiert, dass der Pass nur für Reisen in die Schweiz und nur für einen Monat gültig war und ein Extravermerk enthielt, der eine Verlängerung unmöglich machte.

Es begann mit einem Artikel am 6. September. Darin verlangte das Dagbladet zu erfahren, wer die Verantwortung dafür trug, dass Rolf einen Pass erhalten hatte, damit er außer Landes gelangen konnte. „Norwegischer Nazi als Atomexperte in die Schweiz" und „Bei der Heimkehr erwarten Rolf Widerøe Bußgeld und Einziehung" war auf der Titelseite des Dagbladet zu lesen. Der Text fuhr mit großem Pathos fort:

„Eine der Sachen, der wir uns während des Krieges sicher waren, dass sie nicht geschehen würde, die wir nach dem Krieg hofften, dass sie nicht geschehen würde, und die wir nun fürchten, dass sie künftig immer wieder geschehen, ist vor Kurzem passiert. Die Behörden stellten einem bedeutenden Deutschlandfreund, der zur großen Gruppe jener gehört, denen es gelungen ist, dem Gefängnis knapp zu entgehen, einen Pass aus. (...) Dr. Ingenieur Rolf Widerøe ist in die Schweiz gereist und hat seine Familie mitgenommen. Das gesamte Umfeld in Røa, wo er wohnt, ist selbstverständlich in Aufruhr. Wie das Dagbladet erfahren hat, hat er sich dahingehend geäußert, versuchsweise in die Schweiz auswandern zu wollen, er hat sowohl Auto als auch Hausrat mitgenommen. Die Polizei hat jedoch mitgeteilt, dass eine Verlängerung seines Passes im Ausland nicht möglich sei und er deshalb zurückkehren müsse."

Dann zieht das Dagbladet Rolfs prodeutschen Artikel während des Krieges im Teknisk Ukeblad heran. Es wird darauf hingewiesen, dass ein aktives Mitglied der Nasjonal Samling den Posten des Redakteurs übernommen hatte und dass allein das Einsenden von Artikeln von guten Norwegern als illoyal angesehen wurde. Die Zeitung geht offensiv zu Werke, räumt aber ein:

„Nach dem, was vorliegt, können wir gegen ihn jedoch keine Anklage wegen Spionage erheben.

Etwas anderes ist es, dass er sich für seinen Artikel im Teknisk Ukeblad und andere Sünden verantworten muss, und hier ist mitunter von einem erheblichen Bußgeld und Einzug die Rede."

\section{Die Sachverständigen melden sich zu Wort}

Jetzt meldete sich das Sachverständigenkomitee zu Wort und beteiligte sich aktiv an der Pressedebatte. Der Vorsitzende war besorgt, die Leute könnten glauben, das Komitee habe etwas damit zu tun, dass Rolf seinen Pass 
zurückbekommen hatte. Am 11. September lässt er im Dagbladet deutlich verlauten, dass das Komitee dafür keine Verantwortung trage. Auch dieses Mal landet die Schlagzeile auf der Titelseite, jetzt unter der Überschrift „Der Widerøe-Fall“.

Am 17. September äußert sich mit Gunnar Randers ein anderes Komiteemitglied gegenüber der Zeitung:

„Wir haben keine Reise empfohlen. Es gab auch keine wissenschaftliche Grundlage für seine Schweiz-Reise, wir haben erklärt, dass man ihn als Landesverräter, inklusive der sich daraus ergebenen Folgen, behandeln müsse. Etwas anderes haben wir nicht gesagt."

So war es. Doppelt unterstrichen. Hier sollte keinerlei Zweifel herrschen. Das Komitee hatte keine Reise empfohlen. Auch gab es nichts wichtiges Wissenschaftliches, das unbedingt erledigt werden musste. Im Übrigen müssten Landesverräter die Folgen ihres Tuns tragen. Hoch angesehene Männer konnten nichts hinterlassen, was Grundlage für Zweifel an ihrem Standpunkt in dem Fall bot. Landesverräter waren Landesverräter. So verhielt es sich in diesem Fall.

Professor Brustad steht der Einmischung in die Pass-Angelegenheit durch das Komitee sehr kritisch gegenüber:

„Es ist bedenklich, wenn sich Mitglieder eines Sachverständigenkomitees mit teils heftiger Vorverurteilung eines Beschuldigten in der Presse äußern, unmittelbar bevor der Fall vor Gericht endgültig entschieden werden soll. Besonders schlimm war das im Hinblick auf die Atmosphäre, die während der Behandlung der Landesverratsfälle herrschte, wo der Wille, die Ansichten des Beschuldigten zu unterstützen, nicht vordergründig war."

\section{Keine mildernden Umstände}

Bei all dem gibt es auch eine menschliche Seite, für die sich Tor Brustad interessiert. Von der Verhaftung bis zur vorliegenden Stellungnahme des Komitees waren neun Monate vergangen, und bis der Fall abgeschlossen sein sollte, vergingen weitere neun Monate. Für Rolf und seine Familie geriet diese Zeit zu einer fortwährenden Demütigung, und je länger das Ganze dauerte, desto stärker wurde Brustad zufolge der eine Wunsch: ein schnellstmöglicher Abschluss des Falls, um dann im Ausland ein neues Leben zu beginnen. Brustad zufolge hatte Rolf die Hoffnung, dass seine Tätig- 
keit in Deutschland während des Krieges so aufgefasst würde, wie er selbst es tat, nämlich als ein Projekt von gemeinnützigem, nahezu humanitärem Charakter - einer technologischen Kraftanstrengung zur Verbesserung der Strahlenbehandlung von Krebspatienten. Stattdessen wurde seine Arbeit in Deutschland als Beweis für einen Riss in seiner nationalen Gesinnung gewertet, sagt Brustad und verweist unter anderem auf den Einzug von Lizenzeinnahmen:

„Man folgte nicht dem üblichen Prozedere, das Problem den Steuerbehörden und deren Einschätzung in Verbindung mit Einmalbesteuerung und nachträglicher Veranlagung außerordentlicher Einnahme- und Vermögensverhältnisse $\mathrm{zu}$ überlassen, wie es normalerweise getan wurde. Hingegen zog man schlicht und einfach die Lizenzeinnahmen von etwa 30 Patenten ein."

Er führt auch die Sache mit dem Bruder an:

„Ich meine, es illustriert den Zeitgeist, dass das, was Rolf getan hat, um den Bruder zu retten, nicht als Force Majeure anerkannt wurde. Keine der Initiativen Rolfs, eine Erleichterung der Haftbedingungen zu erzielen, kam als mildernder Umstand zum Ausdruck. Ganz im Gegenteil blieben zwei davon als ausdrückliche Anklagepunkte im Bußgeldbescheid erhalten."

Brustad zufolge scheint Rolfs womöglich bester Karte - dem Bruder helfen zu wollen - seitens der Staatsanwaltschaft keine besondere Bedeutung beigemessen worden zu sein. Dennoch wirkt es verwunderlich, dass Rolf dieses Argument scheinbar nicht angeführt hat. Man kann sich fragen, ob er nicht vielleicht eine noch bessere Trumpfkarte in der Hinterhand hatte.

\section{Verleumdet und nachhaltig geschädigt}

Professor Brustad ist eindeutig der Meinung, dass das Sachverständigenkomitee dazu beigetragen hat, Rolfs Ansehen nachhaltig zu schädigen. Er verweist darauf, dass das Komitee selbst den Wunsch hatte, sein Mandat einzuschränken und den geringstmöglichen Einfluss auf die Entscheidung sowohl der Schuldfrage als auch der Frage zu nehmen, ob Rolf dem Feind Beistand geleistet habe. Allerdings verhielten sich die Sachverständigen hier nicht neutral, behauptet Brustad in seinem Artikel und drückt das ziemlich krass aus:

„Vor dem Hintergrund des Mandats und den selbst auferlegten Zusatzrestriktionen muss ich mit tiefer Enttäuschung feststellen, dass sich das 
Sachverständigenkomitee in der Stellungnahme nicht nur rein sachlicher Argumente bediente, sondern leider auch eine Reihe subjektiver, stark kränkender Charakteristiken der Person Widerøe eingefügt hat: Zum Beispiel belehrte es die Staatsanwaltschaft darüber, dass Widerøes bisherige Arbeit nichts Originelles enthalten habe, was es wert zu erwähnen sei, und dass es auch keinen Grund zu der Annahme gäbe, dass seine zukünftige Arbeit mit dem Betatron von Erfolg gekrönt sei, denn als Physiker sei Widerøe ein Outsider mit minimalem Verständnis von Theoretischer Physik und zudem begrenzten Fähigkeiten als Leiter."

Auch 15 bis 20 Jahre später hält er an seiner Kritik fest und ist der Meinung, das Niedersäbeln durch das Komitee sei ein wesentlicher Grund dafür gewesen, das Rolfs Ansehen in Norwegen verloren ging. Damit schreibt er den Sachverständigen eine große Verantwortung für die Konsequenz des Landesverratsfalls zu. Das tat er damals, als er seine Funde publizierte, und tut es auch heute, obwohl er mittlerweile selbstkritisch sagt, dass er in den 1990er Jahren in seiner Verteidigung von Rolf womöglich sehr weit gegangen sei und entsprechend hart gegenüber dem Komitee war. Er räumt ein, dass er seine Wortwahl hätte mäßigen können. Dass auch er - in seinem Eifer, gute Argumente für Rolf zu finden - voreingenommen und blind für Einwände war. Dies rüttelt jedoch nicht an der Hauptschlussfolgerung aus den Funden im Zentralarchiv. Daran hält er fest, sagt er, und die ist aufsehenerregend genug: Die Dokumente belegen, dass Rolf nichts „Kriegswichtiges" für die Deutschen getan hatte.

Brustad zufolge versagte auch die fachliche Kompetenz der Sachverständigen:

„Dass es dem Komitee an Kompetenz in radiologischer Physik fehlte und es daher nicht verstand, dass Widerøe mit seiner Arbeit einen wichtigen Beitrag dazu geleistet hatte, die Strahlentherapie zu revolutionieren - ein Fachgebiet, das eine direkte Verbindung zur Spezialdomäne der Komiteemitglieder, der Kernphysik, hatte -, das müssen wir so zur Kenntnis nehmen."

Das Kritikwürdige an der Stellungnahme, so sagt er, treffe aber nicht nur Rolf, sondern falle unabhängig davon auf das Ansehen der Sachverständigen sowie, was schlimmer sei, auf den Rechtsapparat an sich zurück:

„Nachdem ich die Dokumente im Zentralarchiv studiert habe, muss ich mit Sorge feststellen, dass die beiden in den Fall involvierten Parteien, sowohl der Rechtsapparat als auch Rolf Widerøe, nachhaltig geschädigt aus dem Prozess hervorgingen." 


\section{Was aber, wenn ...}

Aber angenommen, das Komitee schrieb das, was es schrieb, um Rolf $\mathrm{zu}$ helfen? Das könnte man sich fragen. Zudem spukt im Hinterkopf der Gedanke, dass im Krieg nicht alles genauso wortwörtlich wie sonst gelesen werden sollte. Die Stellungnahme könnte sogar bewusst zweideutig formuliert worden sein, um eine spezielle Absicht zu verfolgen. In diesem Fall hat Professor Brustad mit seiner heftigen Kritik eine solche Auslegung entweder nicht entdeckt oder entschieden, davon abzusehen. Wenn aber die Absicht genau darin bestanden hatte, Rolf als unbedeutend darzustellen, um ihn ungefährlich zu machen, also ihm zu helfen - ja, dann war es zum Beispiel ziemlich schlau, ihn auf „Ingenieur Widerøe“ zu reduzieren, und keine kultivierte Schikane. Denn es lohnt sich - nicht zuletzt als eine Kuriosität - zu bemerken, dass das Komitee Rolf konsequent als „Ingenieur Widerøe" bezeichnet. Er hatte einen Doktortitel, für die Komiteemitglieder aber war er dennoch „Ingenieur“. Er hatte den Grad eines „Dr.-Ing.“ von einer Technischen Hochschule, während die Doktortitel der Komiteemitglieder von Universitäten stammten. Es ist nicht sicher, ob die Verwendung des Titels eine beabsichtigte Abwertung war. Ihn nur als Ingenieur $\mathrm{zu}$ bezeichnen, klingt heute beim Lesen dennoch ein wenig herablassend. Und will man die Stellungnahme in ihrer negativsten Auslegung deuten, kann man die Wortwahl durchaus als Herrschaftstechnik bezeichnen, als einen bewussten Versuch, ihn kleinzumachen. Gleichzeitig war es damals nahezu unhöflich, eine Person nur mit dem Nachnamen zu benennen. Es gehörte sich, dem Namen etwas voranzustellen, „Frau Jensen“ oder „Lehrer Johansen“ ... oder aber „Ingenieur Widerøe“ aus reinem Erfordernis, denn irgendetwas musste dort stehen. Eine nette Deutung könnte daher sein, dass „Ingenieur“ eine praktische Kurzform von „Dr.-Ing.“ ist. Ich tendiere jedoch zur ersteren Version, also dass er in den Augen der Komiteemitglieder Techniker war, während sie sich selbst als intellektuelle Akademiker sahen.

\section{Fachliche Ächtung aus politischem Kalkül?}

Der dänische Professor Søren Bentzen von der University of Maryland School of Medicine in den USA kennt Brustads Arbeit zur Rehabilitierung Rolfs. Seiner Auffassung nach war es für Brustad besonders schlimm, dass ein so bedeutender Norweger und Wissenschaftler wie Rolf Widerøe in seiner Heimat keine Anerkennung fand. 
„Ich glaube in der Tat, dass viele seinen Beitrag nicht einmal erwähnen würden. Das ist wie der Versuch, Hamsun für unzurechnungsfähig zu erklären, ein Versuch, die Person zu schmälern, um sie loszuwerden. Schließlich ist das ein Schandfleck, und darüber war Tor Brustad, in Verbindung mit der Stellungnahme der Sachverständigen, meiner Meinung nach verärgert."

\section{"Wie beurteilen Sie die fachlichen Einschätzungen des Sachverständigenkomitees?"}

„Das ist doch reine Politisierung. Man kann sagen: Wenn jemand Wissenschaft und Politik vermischt hat, dann war es das Komitee, nicht Rolf. Man hatte ein politisches Motiv, um Widerøes Bedeutung zu schmälern. Ich teile Brustads Verärgerung, denn selbstverständlich ist es sinnlos zu sagen, dass er keine wissenschaftliche Arbeit von Bedeutung geleistet habe und dies auch in der Zukunft nicht tun werde. Das ist eine fachliche Fehleinschätzung und zeigt fehlende Einsicht in Widerøes wirkliche Bedeutung. Ich bin ganz sicher, dass sie politische Motive hatten, ebenso wie die Nazis versuchten, die Bedeutung der Arbeit von Albert Einstein herabzusetzen."

„Kannte die Untersuchungskommission seine Forschung gut genug, um begründete Ansichten darüber zu haben?"

„Das weiß ich nicht. Ich weiß nicht genug über die Zusammensetzung und auch nicht, ob sie wirklich über die nötige Expertise verfügten. Widerøe arbeitete in einem Spezialgebiet. Aber ich meine, dass man Widerøe bereits zu diesem Zeitpunkt rein fachlich hätte anerkennen müssen. Ich finde, hier hat man die Dinge vermischt."

\section{"Die Frage ist, ob man sie willentlich vermischt hat."}

„Ich weiß nicht, ob sie es willentlich getan haben. Es gibt vielleicht zwei mögliche Theorien. Eine Theorie ist, dass sie Widerøe in Wirklichkeit gern frei haben wollten. Und wenn man wirklich spekulativ ist, könnte man sagen, das Komitee habe versucht, Widerøe einen Dienst zu erweisen, indem es seine Bedeutung schmälerte. Allerdings grenzt das an umgekehrte Logik. Ich glaube vielmehr, dass sie, von einem fachlichen Standpunkt aus betrachtet, ein Stück minderwertige Arbeit geleistet haben. Und der fachliche Tritt, den sie Widerøe verpasst haben, ist vollkommen widerlich. $\mathrm{Ob}$ aber jemand direkt an den Fäden gezogen hat, ob irgendwo jemand gesessen und gesagt hat: 'Aber, hört jetzt zu, wir sind gezwungen zu sagen, dass Widerøe in Wirklichkeit überhaupt nicht so wichtig ist', das kann ich schließlich nicht wissen, jemand, der dem Komitee beim Schreiben die Hand geführt hat. Vielleicht ist es eher so, 
dass sie versucht haben, Widerøe vom fachlichen Sockel herunterzustoßen, indem sie seine Bedeutung verkleinert haben. Jetzt, später, wissen wir, dass er fachlich recht hatte und seine Prinzipien Ausgangspunkt für eine ganze Industrie wurden. Unabhängig davon bin ich der Meinung, dass die Sachverständigen ihn rein fachlich hätten anerkennen müssen.“

\section{Fünf Physiker}

Die vier Mitglieder des Komitees hatten jeweils einen Doktortitel in Physik, waren im selben Physikverband, gingen zu denselben fachlichen Sitzungen, abonnierten dasselbe Physikmagazin, schrieben Artikel dafür, waren an ihren jeweiligen Karrieren interessiert. Wie Rolf. Dann schrieben sie ihre Stellungnahme für die Staatsanwaltschaft. Über Rolf. Unterzeichneten. Alle vier.

Der Fünfte - Rolf - ist auch im Physikverband, Leser des Mitgliedermagazins, Autor für selbiges, hat einen Doktortitel und ist auf die Karriere fokussiert. Ist einer von ihnen. Und doch nicht. Er war zur falschen Zeit am falschen Ort. Wie sehr identifizierten sie sich mit dem Physiker Widerøe, die vier im Komitee? Wie sehr waren sie von der Stimmung im Land geprägt? Mit anderen Worten: Wie viel Schuld tragen sie daran, dass das Ergebnis so ausfiel, wie es ausfiel? Dass er nicht reingewaschen und von absolut allem freigesprochen wurde? Oder, um es anders zu formulieren: Dass er keine viel ernstere Strafe bekam, wie Finn Lied es angedeutet hat?

Sie trafen auch später aufeinander. Also waren die Interessen und Ressourcen nicht so verschieden, wenn man es herunterbricht. Rolf begegnete sowohl Tangen als auch Randers und Wergeland wieder. Mit dem Vorsitzenden, Hylleraas, wechselte er Briefe - zwar uneins in der Sache, aber beide besonders höflich im Ton. Randers wollte ihn nach dem Krieg außerdem bei der Gründung eines Forschungsinstituts in Norwegen dabeihaben. Und sowohl er als auch Hylleraas setzten sich zu allem Übermaß aktiv dafür ein, dass sich Norwegen an CERN beteiligte, wo Rolf in der Gründungsphase als Berater fungierte.

\section{Ein schlechtes Gewissen}

Sowohl Brustad als auch Waloschek haben mir gegenüber geäußert, dass es den Anschein hatte, eines der Komiteemitglieder, Roald Tangen, habe seither ein schlechtes Gewissen gehabt wegen dem, woran er beteiligt gewesen 
war. $^{52}$ Tangen war an der Universität seinerzeit Brustads Dozent und Doktorvater, wobei dieser immer gestutzt habe, dass Tangen damals für den Inhalt des Sachverständigenberichts hatte bürgen können. Als Brustad in den 1950er Jahren wissenschaftlicher Assistent an der Universität Oslo in Blindern war, kamen sie in einem ihrer Gespräche auf das Thema, wobei Brustad meinte, Tangen habe sich unwohl damit gefühlt, die Stellungnahme unterzeichnet zu haben.

Pedro Waloschek hatte durch seine Korrespondenz mit Tangen denselben Eindruck gewonnen. Im Zusammenhang mit seiner Widerøe-Biografie nahm er Kontakt zu Roald Tangen auf, der damals das einzige noch lebende Mitglied des Sachverständigenkomitees war. Tangen war ihm bei der Beschaffung benötigter Dokumente aus dem Zentralarchiv behilflich, unter anderem des Bußgeldbescheids. Waloschek hatte auch das Archiv direkt angeschrieben, und entweder als direkte Folge oder via Tangen schickte man ihm eine Filmrolle mit einer Kopie des Vergleichsdokuments und der Stellungnahme des Komitees. In der Biografie sind dem Gerichtsverfahren nur einige wenige Abschnitte gewidmet. Waloschek war nicht sonderlich an Details rund um den Bußgeldbescheid interessiert und hat sich im Wesentlichen mit dem Versuch begnügt, das norwegische Wort „forelegg“ zu erklären, das schwer in andere Sprachen zu übersetzen sei und wobei Tangen ihm geholfen hatte.

Er meint, als Tangen das Zentralarchiv aufsuchte, geschah dies aus aufrichtigem Interesse an der Arbeit des Komitees und dessen Auswirkung auf den Fall sowie aus dem Wunsch, zum Buch mit einer möglichst konkreten Darstellung beizutragen. Über die Schlussfolgerung des Komitees sagte Tangen:

„In den Papieren im Reichsarchiv ist dokumentiert, daß die Tätigkeit der Kommission bewirkt hat, daß die erste Anklage bezüglich er Teilnahme Widerøes an der Konstruktion von V-Bomben als grundlos erklärt wurde. Damit war die Anklage auf die allgemeine Tatsache der Arbeit für die Besatzungsmacht reduziert."

Interessanterweise fügte er hinzu:

„Die oben genannte Beurteilungskommission hat übrigens bei der späteren gerichtlichen Verhandlung (im Nov. 1946) keine Rolle mehr gespielt. “53

Wenn es sich so verhält, dass Tangen bereute, die Stellungnahme des Komitees unterzeichnet zu haben, schwächt das ein eventuelles Argu- 
ment, dass das Komitee versucht habe, mit dem Geschriebenen Rolf zu verteidigen. Oder - und das ist weniger vorteilhaft für Tangen - er hat im Nachhinein zu beschönigen versucht, woran er beteiligt war, indem er vorgab, es zu bereuen. Auch in anderen Zusammenhängen ging er darauf ein, und sowohl Brustad als auch Waloschek fassten es so auf, dass Tangen sein Verhalten aufrichtig bedauerte. Das ändert jedoch die Geschichte nicht. Der Bericht war einstimmig. In einem Buch, das Waloschek einige Jahre später über die Waffenentwicklung der Deutschen während des Zweiten Weltkriegs schrieb, geht er auch auf den Briefwechsel mit Roald Tangen ein und schreibt unter anderem:

„Tangen hat mir mehrmals versichert, dass es bei dem vom Expertenkomitee erstellten Gutachten in erster Linie darum ging, Widerøe von den Beschuldigungen zu befreien, an der V2 mitgearbeitet zu haben, was auch vollständig gelungen ist. Die rein wissenschaftliche Betätigung Widerøes in Deutschland wurde dagegen sehr negativ (aber unfair und zum Teil falsch) beurteilt, was dann aber die zuständigen Behörden oder Gerichte überhaupt nicht berücksichtigt haben. “54

Waloschek hat das mir gegenüber vertieft und meint, es habe mitunter den Anschein, als habe Tangen ein schlechtes Gewissen dahingehend, woran er beteiligt war. Bestätigt wird das vom Kernphysiker Olav Aspelund, einem der Teilnehmer des Physiker-Interviews in den Achtzigerjahren, der darin eine Aussage Tangens angeführt hatte:

„Ich habe es mein Leben lang bereut, das unterschreiben zu müssen, aber ich war damals Junior und hatte großen Respekt vor diesen älteren Professoren der Universität in Oslo."

In einer Gesellschaft hatte sich Tangen außerdem einem anderen Mitglied des Sachverständigenkomitees, Gunnar Randers, anvertraut und die Bestätigung erhalten, dass er damit nicht allein war, denn Randers hatte entgegnet: „Das habe ich auch. "55 Anschließend verwies Rolf jedoch auf die überhitzte Stimmung nach dem Krieg und wollte fortfahren, aber Aspelund kam im weiteren Verlauf des Interviews darauf zurück, dass Tangen bezüglich der Stellungnahme des Komitees peinlich berührt gewesen sein soll. Fachlich war der Bericht nicht haltbar, und der Vorsitzende hatte in das Ganze Politik hineingemischt, was er nicht hätte tun sollen. 


\section{Schnee von gestern}

Nicht überraschend ist Rolfs Sicht auf die Arbeit des Komitees entspannt:

„Ich selbst habe nicht viel von diesen Untersuchungen gemerkt, aber ich bin in dieser Richtung recht unempfindlich. Es ist auch denkbar, daß Leute Bösartiges über mich ausgesagt haben, das ich entweder nicht verstanden habe, oder um das ich mich nicht gekümmert habe. (...)

Ich nehme an, daß die Polizeibehörden einfach Experten haben wollten, um einige Fragen zu beantworten, die sie selbst nicht beurteilen konnten. Ich finde das ganz natürlich. Aber die Stimmung in Norwegen war damals überhitzt, und nicht immer wurde alles ruhig und gerecht überlegt und beurteilt. Ich grolle nicht und trage keinem etwas nach. Aber damals fand ich es doch recht gut und günstig, daß ich bald danach in der Schweiz meine Arbeit wieder aufnehmen konnte. “56

Eine plausible Erklärung dafür, warum er in diese schwierige Lage geriet, hat er nicht, außer dass er als Angestellter bei NEBB „einberufen“ worden war, in Deutschland zu arbeiten. Auch das Komitee gab darauf keine eindeutige Antwort. Nach Durchsicht der Unterlagen war Tor Brustad zu der Auffassung gelangt, dass „weder das Sachverständigenkomitee noch der alliierte Nachrichtendienst jemals die wirklichen Gründe dafür gefunden hat, warum Rolf im Spätherbst 1943 in das Betatron-Projekt in Hamburg eingestiegen ist". 57

Auch andere haben den Versuch unternommen. In dem von einigen jungen Physikern in Oslo arrangierten Interview mit dem 81-jährigen Rolf wurde er unter anderem zu seiner Begegnung mit dem Gerichtswesen und seiner Sicht auf die Arbeit der Sachverständigen befragt. Die Tonbandaufnahme von dem Gespräch wurde von einem Sekretär niedergeschrieben, allerdings wurde dieses Dokument nie veröffentlicht und ist in dem Forschungsinstitut, in dem das Interview stattfand, nicht mehr zugänglich. In den USA existiert jedoch eine Kopie. ${ }^{58}$ Der Einzige, der sich neben den Initiatoren eigentlich für das Gespräch interessierte, war Rolf selbst. Er las die 116 maschinengeschriebenen Seiten gründlich Korrektur und fügte dem Text zudem eine Anlage bei. Später übersetzte er für Waloschek alles eigenhändig ins Deutsche, wobei er mit blauem Kugelschreiber auf das übliche karierte Papier schrieb. Späterhin überließ Waloschek mir sein komplettes Widerøe-Archiv, inklusive der Übersetzung des aufgezeichneten Gesprächs. 
Im Verlauf des Interviews kamen die Physiker auf das Gerichtsverfahren zu sprechen - Teile davon werden nachfolgend wiedergegeben. Dabei ist hilfreich zu bedenken, dass hier ein alter Mann spricht. Dass im Laufe der Jahre möglicherweise einiges vergessen, einiges verdrängt und einiges „beschönigt" wurde. Dass er sich aber zuerst so stark in der Niederschrift und dann in der Übersetzung engagierte und sie anschließend als Grundlage für die Biografie weiterreichte, bedeutet, dass er sich auch im Nachhinein zu seinen Aussagen bekannte und wollte, dass sie für die Nachwelt so erhalten blieben. ${ }^{59}$ Es ist der Mühe wert zu sehen, wie er sich ausdrückte und welche Fragen er schnell abhandelte. Thema war sein fachlicher Einsatz, aber auch andere Aspekte kamen zur Sprache. Als er gefragt wurde, wie lange er im Gefängnis war, übernahm Rolf schnell die Regie:

\section{Rolf Widerøe:}

„Nun, ich erinnere mich nicht, es waren ein paar Monate, glaube ich, oder sowas. Und ich bekam einen Pass und reiste in die Schweiz. (...) Und ich war mir im Klaren darüber, dass es vollkommen ausgeschlossen war, das Betatron in Norwegen zu bauen, es gab keinerlei Grundlage für die Vakuumtechnik oder für die Glastechnik oder sowas. Zumindest war mir so etwas nicht bekannt. (...)"

Jan Vaagen:

„Waren Sie während des gesamten Krieges bei Norsk Brown Boveri angestellt?"

Rolf Widerøe:

"Ja."

Jan Vaagen:

„Half das dabei, den Ilebu-Aufenthalt zu verkürzen, als Sie wieder im Land waren?"

\section{Rolf Widerøe:}

„Ich glaube nicht, dass es möglich war, daran zu rütteln. Etwas aber war seltsam. Randers erhielt den Auftrag - er war drüben in Amerika -, nach Norwegen zu reisen und mich auszufragen. Also traf ich ihn in Grini, und wir wurden recht gute Freunde, sprachen über alles Mögliche. Denn verstehen Sie, der Grund, warum ich nach Grini kam, war, dass die Nachbarn in Røa wussten, dass ich Ahnung von Relais hatte, und daher glaubten sie, ich sei der Erfinder der V2-Rakete. Und das wäre natürlich eine entsetzliche Sache gewesen. Und deshalb kam ich nach Grini. Und deshalb kam Randers 
nach Norwegen, um mich diesbezüglich auszufragen. Und ich erklärte es ihm schnell - ich erzählte ihm natürlich alles so, wie es war, und er begriff schnell, dass das mit der V2-Rakete nur Unsinn war. Danach gab es für mich keine größeren Schwierigkeiten."

Dann wollte Vaagen wissen, ob Rolf in der Zeit, als er nach dem Krieg in Norwegen war, Kontakt zu norwegischen Kollegen hatte.

\section{Rolf Widerøe:}

„Ich habe mit Hylleraas gesprochen [dem Vorsitzenden des Komitees, von mir hinzugefügt], und er war mir gegenüber sehr skeptisch. Er sagte in etwa zu mir: 'Es geht nicht, das hier zu einer wissenschaftlichen Arbeit zu machen.' Ansonsten hatte ich während des Krieges ein wenig Kontakt zu Wergeland gehabt, und er war mir gegenüber sehr reserviert. Anfangs, beim ersten Mal, war er sehr nett und wir sprachen offen über alles Mögliche, später aber war er sehr reserviert. Als Grund dafür vermute ich, dass die Leute über das eine oder andere geredet haben. Man hat mich bestimmt als eine ziemlich entsetzliche Person bezeichnet. (...) Wie ist es, lebt Hylleraas noch?“

\section{Olav Aspelund:}

„Nein, er ist tot. Er musste tot sein, damit Sie hier in Oslo als Mitglied der Wissenschaftsakademie vorgeschlagen wurden, das kann ich auch ganz direkt so sagen."

\section{Rolf Widerøe:}

„Ah ja, jawohl, ja.“

Jan Vaagen fragt, ob der Bericht des Komitees ein Auftragswerk war und welchen Hintergrund dies eventuell gehabt haben könnte. Rolf lässt sich diesbezüglich nicht auf Spekulationen ein und fährt damit fort, was er für wichtig hält:

\section{Rolf Widerøe:}

„Ich gehe davon aus, dass es schlicht und einfach die Polizeibehörden waren, die Expertise in einer Frage wollten, die sie selbst nicht beurteilen konnten. Und ich fand das auch nicht seltsam und habe anschließend auch keinem dieser Menschen etwas nachgetragen, denn das Einzige, was meiner Meinung nach gut und günstig war, ist, dass ich die Erlaubnis erhielt, in die Schweiz zu reisen und dort so schnell wie möglich mit der Arbeit zu beginnen. (...) Und schließlich weiß ich, dass die Atmosphäre in Norwegen zu dieser Zeit, rein politisch, sehr schwierig war. Sie war überhitzt, und man konnte nicht erwarten, dass es immer ganz gerecht, schön und ordentlich zuging. Ich 
kann all das verstehen, und ich habe alles zusammen hinter mir gelassen und vergessen. Dass ich jetzt hier darüber rede, ist im Grunde also höchst überflüssig."

Olav Aspelund äußert seine Ansicht, dass die Universität Oslo fachlich hier nicht sonderlich gut weggekommen sei:

„Das kann ich sagen, da ich die Stimmung am Physik-Institut kenne. Deshalb musste ich auch eine Barriere niederreißen, als ich Sie einlud. Aber es lief ganz hervorragend, unter anderem Tangen benahm sich wie ein Mann."

Jan Vaagen interessiert sich für das Prinzipielle, wenn einer, dessen Meriten hauptsächlich in der technischen Tätigkeit liegen, von einem akademischen Komitee beurteilt wird, dessen Kompetenz sich ganz an der Peripherie seiner eigenen bewegt. Sowohl Rolf als auch mehrere andere sind einig darin, dass die Komiteemitglieder Theoretiker ohne Erfahrung in der Experimentalphysik waren. Aaserud will die Diskussion wieder auf Spur bringen und rundet mit dem Satz ab: „Hier gibt es viele Unbekannte.“ Dem stimmt Rolf $\mathrm{zu}:$

Rolf Widerøe:

„Ich glaube, wir vergessen den Schnee, der im vergangenen Jahr gefallen ist.

Das ist das Beste, was man tun kann."

Jan Vaagen:

„Ja, ich glaube, wir sollten zum fachlich Interessanten zurückkehren, dieses Intermezzo hat trotz allem in gewissen Kreisen Nachklang gehabt, was meines Erachtens nach unangenehm war."

\section{Rolf Widerøe:}

„Ich habe nichts bemerkt. Aber ich bin in dieser Hinsicht vermutlich so unempfindlich, dass es gut sein kann, dass Leute Verdächtigungen vorgebracht haben und ich das Gemunkel entweder nicht richtig verstanden oder mich schlicht und einfach nicht darum gekümmert habe."

\section{Jan Vaagen:}

„Ich glaube, wir können dabei so weit gehen, dass in dem Buch über Lawrence und Oppenheimer etwas dahingehend steht, dass zu dieser Zeit Ihre Staatsbürgerschaft in Gefahr war. Etwas in dieser Richtung."

\section{Rolf Widerøe:}


„Nicht die Spur, nicht die Spur. (...) Ich hatte zum Beispiel keine Schwierigkeiten, einen Pass zu bekommen."

\section{Sind Fakten dasselbe wie die Wahrheit?}

Die Aussage über den Pass kann unbesorgt als eine im Nachhinein erschaffene beschönigte Version der Wirklichkeit bezeichnet werden. Und wenn er angibt, nicht zu wissen, wie lange er im Gefängnis gesessen hat, kokettiert er. In dem von ihm unterzeichneten Bußgeldbescheid steht die genaue Anzahl an Tagen, die er in Untersuchungshaft verbracht hat, nämlich 47. Vergisst man so etwas? Vergisst jemand, der mit Zahlen arbeitet, so etwas? Und allein dadurch, dass er Randers die eigentlichen Zusammenhänge erklärte, „gab es keine größeren Schwierigkeiten“ für ihn. Ja, so kann man es auch ausdrücken. Das muss die weltgrößte Untertreibung sein. $\mathrm{Ob}$ das Verdrängung oder dem bewussten Wunsch geschuldet war, eine wohlfrisierte Darstellung abzugeben, ist schwer zu beurteilen. Vielleicht ein bisschen von beidem. Als der ältere Herr, der er zum Zeitpunkt des Interviews war, verfügte Rolf vermutlich über eine „eingeübte“ Art und Weise, über diese Ereignisse zu sprechen. Oder über eine gewisse selektive Erinnerung, wenn man es lieber so ausdrücken möchte. Das zeigte sich auch zehn Jahre später, als Pedro Waloschek hinsichtlich der Biografie mit ihm zusammengearbeitet hat. Rolf sagte, er sei freigesprochen worden. Waloschek hat das mir gegenüber vertieft:

„Es ist dokumentiert, dass er das gesagt hat. Aber er sagte nicht immer die Wahrheit."

„Sie müssen erklären, was Sie damit meinen."

„Nun, das ist ein unschöner Teil der Geschichte.“

"Okay."

„Fakt ist, dass er darauf bestand, in Norwegen freigesprochen worden zu sein. Und als er mir das im Rahmen eines Videointerviews erzählte, rief mich seine Frau in die Küche und sagte: 'Er sagt nicht die Wahrheit. Er hat den Bußgeldbescheid akzeptiert. Er hat ihn unterschrieben. Er bekam ein Bußgeld. Ihm wurde auf Lebenszeit verweigert, Teil der norwegischen Armee zu sein, und er wurde nie wieder eingezogen. Sachen, die er ausgezeichnet weiß. Der 
Bußgeldbescheid wurde akzeptiert. Und er hat ihn, in seinem Kopf, zu einem Freispruch verdreht.'“

Dann fügt er hinzu, dass Rolfs Frau seiner Meinung nach ehrlich war, als sie unmittelbar sagte: „Stopp, Achtung! Das stimmt nicht.“ Das war der Grund, warum Waloschek anfing, die Sache genauer zu untersuchen, und sich Kopien vom norwegischen Zentralarchiv besorgte, vor allem eine Kopie des Bußgeldbescheids mit Rolfs Unterschrift.

Aber vielleicht ist Waloschek hier trotzdem ein bisschen zu streng. Freigesprochen? Es fragt sich wovon. Von allem? Nein. Nicht von dem Artikel im Teknisk Ukeblad. Nicht von dem Geld für die Freiwilligen-Legion Norwegen. Nicht von der Tatsache, dass er für den Feind gearbeitet hat. Nun, vielleicht nicht. Aber von dem Entsetzlichen. Der Waffenanschuldigung. Dem eigenen Ermessen nach also „freigesprochen“. Nicht im Sinne des Gesetzes. Nicht nach Ansicht der Leute. Und auch nicht nach der Ragnhilds. Offensichtlich.

Die meisten Leute wussten nichts von dem, was vor Gericht geschah. Die Medien hatten sich in Sachen der Passfrage engagiert, nicht aber in dem Fall als solchen. Das war zum Teil dem Umstand geschuldet, dass nach Unterzeichnung des Bußgeldbescheids alle zum Fall gehörenden Dokumente automatisch mit dem Geheimhaltungsstempel versehen wurden. So war es. Bei einem gewöhnlichen Prozess hätte die Gesellschaft den Verhandlungen vor Gericht leichter folgen und Einblick sowohl in die Anklage als auch in das Prozedere des Anklägers und des Verteidigers erhalten können. Jetzt wurden die Unterlagen einfach archiviert.

Dann vergehen weitere Jahre. Es kommen weitere Fakten ans Licht. Er war dort. Er hat das getan. Zusammen mit ihnen. Dann wissen wir also, was passiert ist? Ja? Wir wissen etwas von dem, was er gesagt und geschrieben hat. Ja. Auch, was andere gesagt und geschrieben haben. Aber nur das, was gefunden wurde. Möglicherweise existiert mehr. Weitere Dokumente. In anderen Ländern. Weitere Involvierte. Menschen, die versprochen oder sich aus irgendeinem Grund entscheiden haben, nichts zu sagen.

Das Zentralarchiv wurde besucht. Die Unterlagen im Fall auf Landesverrat Nr. 3418/45 gelesen und Interviews geführt. Das, was einst über den Fall geschrieben wurde, ist bekannt. Kommentare sind veröffentlicht. Zentrale und aufsehenerregende Fakten, die sich niemand anzupacken gewagt hatte, wurden aufgedeckt. Dank zweier Männer, einem in Oslo und einem in Hamburg. Brustad, Professor am Radiumhospital, veröffentlichte seinen Artikel in der Zeitschrift Acta Oncologica. Arrangierte eine Konferenz. Rief den Widerøe-Preis ins Leben und platzierte Rolfs Büste in einer Glasvitrine 
im Vestibül des Krankenhauses. Waloschek, in Hamburg, gab sein Buch heraus. Ließ es ins Englische und Russische übersetzen.

Damit war das internationale Fachmilieu in Kenntnis gesetzt worden: Rolf hätte nie verhaftet werden sollen. Er hatte „dem Feind“ keinen „Beistand geleistet". Hatte nie mit den V2-Raketen zu tun gehabt. Die Fakten lagen auf dem Tisch. Gut. Wissen wir dann also alles? Warum er 1943 nach Deutschland ging? Warum er im April 1945 plötzlich nach Hause zurückkehrte? Verstehen seine Reaktion besser, als er nach dem Verfahren in die Schweiz „Hloh“? Haben Einblick bekommen, wie es sich angefühlt hat, 50 Jahre lang im Exil zu leben? Verstehen mehr vom Menschen Rolf Widerøe? Haben wir ihn jetzt? Ja. Und nein.

Sind Fakten dasselbe wie die Wahrheit? Tja. Und selbst wenn es so ist, kann man dann sicher sein, alle Fakten gefunden zu haben? Diese Fragen können wir im Nachhinein gern stellen, aber das Leben wird im Hier und Jetzt gelebt. Mit Frau und Kindern, Arbeit und alten Eltern zu Hause. Kann das alles zu Faktoren in einer Gleichung abgebildet werden, die aufgeht? In einer Welt, die schwarz-weiß ist? In der Rechtswissenschaft, ja. Im Leben, nein. Das „neunmalkluge Gerede“ anderer und lose Gerüchte bringen jedoch mehr durcheinander als nötig, und es gibt sehr viele unbekannte Faktoren. So viele, dass man leicht noch mehr Durcheinander verursacht. Mit sicherem historischem Abstand denke ich: Wie konnte er in so etwas navigieren?

Diejenigen, die ihm am nächsten standen, fanden das, was er tat, gewiss nicht so seltsam. So war er, an seiner Forschung interessiert. Oder doch, es war seltsam. Er selbst zuckte mit den Schultern und verließ das Land damals 1946.

Mit erhobenem Haupt und geradem Rücken, den Blick weit nach vorn gerichtet, auf einen Punkt irgendwo dort draußen in der Welt. Komme, was wolle. Quoi qu'il arrive. Come what may.

\section{Anmerkungen}

1. Dokument x. O. Pk. VJ 3418, 46-47. Bericht A, Nr. 1029. Zentralarchiv, Landesverrat-Fall Nr. 3418/45 (Klausul).

2. Dokument 2, 1003, 24.5 45, Zentralarchiv, Landesverrat-Fall Nr. 3418/45 (Klausul).

3. Dokument 8, per Hand geschrieben: „Redegjørelse for mitt arbeid i Tyskland etc." (Bericht über meine Arbeit in Deutschland etc.), 24/545, Zentralarchiv, Landesverrat-Fall Nr. 3418/45 (Klausul).

4. Tor Brustad: „Why is the Originator of The Science of Particle Accelerators so Neglected, Particularly in his Home Country?" Voll- 
ständige Version. Scandinavian University Press 1998. ISSN 0284-186X (gekürzte Version ohne Fußnoten in Acta Oncologica 1998, 37), Sonderdruck des kompletten Artikels, S. 10

Brief von Ingenieur S. A. Solberg, A/S Norsk Elektrisk \& Brown Boveri, 25. Mai 1945 an die Kriminalpolizei Oslo, Møllergt. 19, Oslo.

5. Brief von Rolf Widerøe an Direktor Solberg, 22. Januar 1946, ETHBibliothek Zürich HS 903:80.

6. Dokument 11 Rettsbok for Oslo Forhørsrett, datiert 25. Juni 1945, gehalten im Ila-Gefängnis. Zentralarchiv, Landesverrat-Fall Nr. 3418/45 (Klausul).

7. Dokument 18. O. Pk, V Fall 3418; die Erklärung wurde dem Amtsgericht vorgelegt 25/6-45. Zentralarchiv, Landesverrat-Fall Nr. 3418/45 (Klausul).

8. Oscar de Besche, Dokument, datiert 5. Juli, adressiert an den Polizeibevollmächtigten Gustav B. Dreyer, Zentralarchiv, Landesverrat-Fall Nr. 3418/45 (Klausul).

9. Dokument 17. O. Pk. V, Oslo 7/7 1945, Freilassungsbefehl, Zentralarchiv, Landesverrat-Fall Nr. 3418/45 (Klausul).

10. Dokument 19. Rettsbok for Oslo Forhørsrett, 21/11 45, Zentralarchiv, Landesverrat-Fall Nr. 3418/45 (Klausul).

11. 1942 wurde diese Arbeit an der Universität Oslo fortgeführt, wo der leitende Professor der Entwicklung, Johan P. Holtsmark, zum Professor ernannt worden war. Die beiden begleiteten ihn nach Oslo. An einzelnen Stellen wird auch behauptet, dass Holtsmark dem Sachverständigenkomitee angehört habe. Die vier Ernannten, die auch das Abschlussdokument unterschrieben, waren jedoch Hylleraas, Wergeland, Tangen und Randers.

12. Hemmer, Per Chr. und Ivar Svare: Linjen for Teknisk fysikk ved NTH og dens videreføring 75 år 1932-2007.

13. Er gehörte der wissenschaftlichen Geheimdienstorganisation Operation Alsos (oder Alsos Mission) in den USA an.

14. Schreiben vom 24.9.1945 an Kriminalchef L'Abeé-Lund von P.Bm. Gustav B. Dreyer, Zentralarchiv, Landesverrat-Fall Nr. 3418/45 (Klausul). Die beiden betreffenden Anlagen waren die Dokumente Nr. 14 und 15. Betrifft Kapitel dieses Buches „Aber da war mehr ...“, „dass Randers für den amerikanischen Geheimdienst tätig war“.

15. U. a. laut einem der Mitglieder, Roald Tangen, im Gespräch mit Pedro Waloschek in Verbindung mit der Widerøe-Biografie.

16. Die anderen sind von Hermann Dänzer, Walter Müller und dem späteren Nobelpreisträger Walther Bothe. 
17. Dokument 25, datiert 11. März 1946. Schreiben an die Polizeibehörde Oslo und Aker, Abteilung Landesverrat, Viktoria Terrasse 5/7, vom Anwalt des Höchsten Gerichts Oscar de Besche, Zentralarchiv, Landesverrat-Fall Nr. 3418/45 (Klausul).

18. Dokument 27, datiert 15. März 1946. Bericht an die Polizeibehörde Oslo, abgegeben von Krim.ass. John Strand, Zentralarchiv, Landesverrat-Fall Nr. 3418/45 (Klausul).

19. Dokument 33, datiert 24. Mai 1946, von Brown Boveri an Rolf Widerøe, Zentralarchiv, Landesverrat-Fall Nr. 3418/45 (Klausul).

20. Dokument 45 mit Anlage, Brief vom Kgl. Außenministerium an Herrn Reichspolizeichef, Oslo, datiert 12. Juni 1946, „Dr. ing. Rolf Widerøes forhold under krigen“, Zentralarchiv, Landesverrat-Fall Nr. 3418/45 (Klausul).

21. Dokument 28, datiert 29. Juni 1946, O. Pk. V. J.5154, Schreiben von Hr. Anw. O. de Besche an die Polizeibehörde Oslo und Aker, Zentralarchiv, Landesverrat-Fall Nr. 3418/45 (Klausul).

22. Verhör von Rolf Widerøe, durchgeführt von P.bm. Dreyer, 4. Juli 1946, Zentralarchiv, Landesverrat-Fall Nr. 3418/45 (Klausul).

23. Schreiben von Hr. Anw. O. de Besche an die Polizeibehörde Oslo und Aker, datiert 6. Juli 1946, Zentralarchiv, Landesverrat-Fall Nr. 3418/45 (Klausul).

24. Brief von Viggo Widerøe an P.bm. Gustav B. Dreyer, 8. Juli 1946, Zentralarchiv, Landesverrat-Fall Nr. 3418/45 (Klausul).

25. Dokument 32, Bericht an die Polizeikammer Oslo, 1. August 1946, abgegeben von P.bm. Gustav B. Dreyer am 31. Juli 1946, Zentralarchiv, Landesverrat-Fall Nr. 3418/45 (Klausul).

26. Tor Brustad: „Why is the Originator of The Science of Particle Accelerators so Neglected, Particularly in his Home Country?" Vollständige Version. Scandinavian University Press 1998. ISSN 0284-186X (gekürzte Version ohne Fußnoten in Acta Oncologica 1998, 37), Sonderdruck des kompletten Artikels, S. 8, Fußnote 17. Schreiben datiert 11. Juli 1946 von P.bm. Gustav B. Dreyer an den Kriminalchef, Polizeibehörde Oslo, Abteilung Landesverrat. Areal: AB 3418, Zentralarchiv (Klausul).

27. Notiz (separate Mappe) Ing. Rolf Widerøe, Fall 3418/45 - AB, datiert 22.7.1946, wahrscheinlich von L. L'Abee-Lund an Gustav B. Dreyer, Zentralarchiv, Landesverrat-Fall Nr. 3418/45 (Klausul).

28. Brief von Gustav B. Dreyer an Kriminalchef L. L'Abee-Lund vom 14.9.1946, Betr. Fall Rolf Widerøe, Zentralarchiv, Landesverrat-Fall Nr. 3418/45 (Klausul). 
29. Dokument 52, Bericht an die Polizeibehörde Oslo, datiert 11.10.1946 bei P.bm. Gustav B. Dreyer, Zentralarchiv, Landesverrat-Fall Nr. 3418/45 (Klausul).

30. The First Scandinavian Symposium on Radiation Oncology. Seminar in memory of professor dr. ing. Rolf Wideøe. Baroniet Rosendal, 24.-28. Mai 1997.

31. Tor Brustad: „Why is the Originator of The Science of Particle Accelerators so Neglected, Particularly in his Home Country?" Acta Oncologica 1998, S. 37, Scandinavian University Press 1998 (verkürzte Version ohne Fußnoten). In derselben Ausgabe finden sich auch zwei weitere Beiträge des Seminars über Widerøe; Autoren sind Anders Brahme und B. H. Wiik.

32. Im Gespräch am 16. September 2009. Lied starb am 10. Oktober 2014.

33. Anlage „Ad Stråletransformatoren“.

34. Brustad: "Why is the Originator ...".

35. Waloscheks Videointerview wurde an zwei Tagen, dem 22. und 23. Oktober 1992, aufgenommen und in einer Ausstellung im Museum für Gestaltung in Zürich vom 3.3. bis 2.5.1993 gezeigt. Das auf Deutsch geführte Interview wurde auch für die Biografie verwendet.

36. Brustad: „Rolf Widerøe: Eminent vitenskapsmann - fotnote i norsk fysikk?", Forskningspolitikk, Nr. 3, 1997.

37. Brustad: "Why is the Originator ...".

38. Brustad: "Why is the Originator ...".

39. Brustad: „Why is the Originator ...", kompletter Artikel, Fußnote 20: Schiebold war ein deutscher Physiker, der vorgeschlagen hatte, dass, wenn man durch technologische Entwicklung Röntgenstrahlen mit hoher Energie und Intensität erzeugen könnte, es möglich sein könnte, einen Bleistift-Strahl von Röntgenstrahlen auf feindliche Flugzeuge zu richten. Die feindlichen Piloten könnten auf diese Weise eine tödliche Strahlendosis erhalten, und der Strahl könnte sogar das Radarsystem des Feindes stören, so dass die Flugzeuge ihre Ziele aus den Augen verlieren und Probleme haben würden, „ihren Weg nach Hause zu finden“.

40. Brustad: „Why is the Originator ...", Fußnote 21.

41. Einstellung des Sachverständigenkomitees, S. 7.

42. Dokument 14 und 15 an das Sachverständigenkomitee, Zentralarchiv, Landesverrat-Fall Nr. 3418/45.

43. Hier verweist Tor Brustad auf Fußnote 23 des Artikels „Why is the Originator ..."In dem von Pedro Waloschek zusammengestellten und herausgegebenen Buch The Infancy of Particle Accelerators, Life and Work of Rolf Wideroe, Vieweg 1994, stellt Wideroe fest: 'Ich erklärte mich also 
bereit, nach Hamburg zu gehen, oder genauer gesagt, ich wurde durch mehr oder weniger freiwillige Zustimmung (und offensichtlich die meines Arbeitgebers NEBB) ,zur Arbeit gezwungen'.

44. Norwegens offizielle Statistik XI. 179. Statistik über Landesverrat 19401945. Statistisches Zentralbüro. Oslo 1954. (Fußnote 1).

45. Über die Einstellung der Verfolgung von Landesverrat vom Justizministerium an das Parlament, 11. Januar 1962. Die offiziellen Zahlen sehen wie folgt aus: Insgesamt wurden 92.805 Personen des Landesverrats beschuldigt, 342 der Kriegsverbrechen. 28.750 wurden verhaftet, die höchste Anzahl Gefangener gab es im Juli 1945, ca. 14.000 verteilt auf 200 Lager. 30 Personen wurden wegen Landesverrat zum Tode verurteilt, 15 wegen Kriegsverbrechen. Ca. 17.000 wurden zu einer Gefängnisstrafe verurteilt, ca. 25.000 zu Bußgeldern, ca. $7500 \mathrm{zu}$ anderen Strafen, ca. 1400 wurden freigesprochen, ca. 5500 wurde die Anklage erlassen und ca. 37.000 Fälle wurden nach Beweislage eingestellt.

46. Tor Brustad: „Why is the Originator ...“, vollständige Version, Fußnote 13. (Das ist das erste Mal, dass Rolf erwähnt, dass das Radiumhospital ein Betatron bestellt hat. Dabei muss es sich um das 15-meV-Betatron handeln, eine Bestellung, aus der nie etwas geworden ist. Eine Bestellung erfolgte erst in den 1950er Jahren, woraufhin das Krankenhaus sein 31-meV-Betatron erhielt.) Dokument 24. Schreiben von Rolf Widerøe an den Polizeibevollmächtigten Dreyer, datiert 1/3 46, O. Pk. J. 3418, 46-47 „betr. Dr. Widerøes Ersuchen um Reiseerlaubnis“, Zentralarchiv, Landesverrat-Fall Nr. 3418/45 (Klausul).

47. Im Interview mit Tor Brustad. Vermutlich ist Chefingenieur Torleif Kaulun Torstensen gemeint.

48. Antwortschreiben des Sachverständigenkomitees an den Polizeibevollmächtigen Gustav B. Dreyer. Mit dem Vermerk „ZentralarchivDokument“. Tor Brustad: Acta Oncologica 1998, 37.

49. ETH-Bibliothek, Archiv, HS 903:239 Rolf Widerøe, Brief an die Polizeibehörde Oslo und Aker, Røa, 7.6.1946.

50. ETH-Bibliothek, Archiv, HS 903:239 Rolf Widerøe, Brief an den Kriminalchef, Røa, 2.8.1946.

51. ETH-Bibliothek, Archiv, HS 903:239 Rolf Widerøe, Brief an Oscar de Besche, Zürich 3.9.1946.

52. In Gesprächen in Verbindung mit diesem Buch.

53. Biografie, S. 99.

54. Waloschek: Todesstrablen, S. 178-179. 
55. Physiker-Interview in Oslo, 12. Juli 1983, Untersuchungsinstitut von NAVF, dem heutigen Nordischen Institut für Studien von Forschung, Innovation und Ausbildung in Oslo. In seiner deutschen Übersetzung schreibt Rolf, dass es der 11. Juli war, sein Geburtstag. Richtig ist wahrscheinlich der 12. Juli. Die Abschrift des Forschungsinstituts ist auf den 14. März 1984 datiert.

56. Biografie, S. 106.

57. Brustad: „Why is the Originator ...".

58. Niels Bohr Archives, American Institute of Physics.

59. Veranstalter war das Untersuchungsinstitut von NAVF in Oslo. Die Teilnehmer waren: Stipendiat Finn Aaserud, Jan Vaagen (Universität Bergen), Olav Netteland (Radiumhospital Oslo), Staatsstipendiat Olav Aspelund und Gunnar Thoresen (Technisches Museum). Im Hintergrund aktiv war Institutsleiter Hans Skoie.

Open Access Dieses Kapitel wird unter der Creative Commons Namensnennung - Nicht kommerziell - Keine Bearbeitung 4.0 International Lizenz (http:// creativecommons.org/licenses/by-nc-nd/4.0/deed.de) veröffentlicht, welche die nicht-kommerzielle Nutzung, Vervielfältigung, Verbreitung und Wiedergabe in jeglichem Medium und Format erlaubt, sofern Sie den/die ursprünglichen Autor(en) und die Quelle ordnungsgemäß nennen, einen Link zur Creative Commons Lizenz beifügen und angeben, ob Änderungen vorgenommen wurden. Die Lizenz gibt Ihnen nicht das Recht, bearbeitete oder sonst wie umgestaltete Fassungen dieses Werkes zu verbreiten oder öffentlich wiederzugeben.

Die in diesem Kapitel enthaltenen Bilder und sonstiges Drittmaterial unterliegen ebenfalls der genannten Creative Commons Lizenz, sofern sich aus der Abbildungslegende nichts anderes ergibt. Sofern das betreffende Material nicht unter der genannten Creative Commons Lizenz steht und die betreffende Handlung nicht nach gesetzlichen Vorschriften erlaubt ist, ist auch für die oben aufgeführten nicht-kommerziellen Weiterverwendungen des Materials die Einwilligung des jeweiligen Rechteinhabers einzuholen. 